\title{
INEFFICIENT PROCUREMENT IN TIMES OF PANDEMIA
}

\author{
JORGE GALLEGO $^{\dagger}$, MOUNU PREM $^{\ddagger}$, AND JUAN F. VARGAS ${ }^{\star}$
}

\begin{abstract}
The public health and economic crisis caused by the COVID-19 pandemic has pushed governments to substantially and swiftly increase spending. Consequently, public procurement rules have been relaxed in many places to expedite transactions. However, this may also create opportunities for inefficiency and corruption. Using contract-level information on public spending from Colombia's eprocurement platform, and a difference-in-differences identification strategy, we find that municipalities classified by a machine learning algorithm as more prone to corruption react to the spending surge by using a larger proportion of discretionary non-competitive contracts and increasing their average value, especially to procure crisis-related items. In these places, contracts signed during the emergency are more likely to have cost overruns, be awarded to campaign donors, and exhibit a range of implementation inefficiencies. Our evidence suggests that large negative shocks such as the recent COVID-19 pandemic may increase waste and corruption.
\end{abstract}

Keywords: Corruption, COVID-19, Public procurement, Machine learning

Date: May 11, 2021.

We would like to thank Gabriele Gratton, Jennifer Hunt, Nelson Ruíz, Tara Slough, Mateo Uribe, and seminar participants at U. de San Andrés, Banco de la República, DNP, OVERS, Harvard, NYU, LACEA IEN, IDB, Fedesarrollo, University of Pernambuco, Quantil, and HiCN, for helpful comments. We also thank Misión de Observación Electoral, Contraloría General de la República, and Luis Martínez for sharing with us data used in this project. Erika Corzo and Andrés Rivera provided excellent research assistance. Declaration of interest: none.

${ }^{\dagger}$ School of Economics, Universidad del Rosario. email: jorge.gallego@urosario.edu.co.

${ }^{\ddagger}$ School of Economics, Universidad del Rosario. email: francisco.munoz@urosario.edu.co.

${ }^{\star}$ School of Economics, Universidad del Rosario. email: juan.vargas@urosario.edu.co. 


\section{INTRODUCTION}

The COVID-19 pandemic rapidly expanded throughout the entire world in the first half of 2020. In an effort to control the spread of the disease, many governments established stringent lockdown measures that restricted the mobility of hundreds of millions and paralyzed large sectors of the economy (Acemoglu et al., 2020; Ludvigson et al., 2020). Consequently, in addition to the large investments in medical infrastructure and related supplies, billions have been allocated for poverty relief and to support vulnerable businesses. This paper argues that the need of governments to quickly spend large amounts of resources increases discretion, which in turn may translate into inefficiency and corruption opportunities in public procurement.

In many countries, COVID-driven spending needs have forced governments to relax public procurement protocols (De Michele and Cruz, 2020). ${ }^{1}$ Easing procurement rules increases the discretion of public officials, which may create waste, favoritism, and corruption opportunities that could offset the full potential benefits of the policies aimed at promoting short-term relief spending in the face of large negative shocks. Indeed, there is widespread evidence that discretion in procurement may result in inefficiencies and corruption (Transparency International, 2010; Tran, 2011; Palguta and Pertold, 2017; Decarolis et al., 2020; Baltrunaite et al., 2018; Kang and Miller, 2017). ${ }^{2}$ Using administrative data for almost 360,000 contracts procured in Colombia around the first confirmed COVID-19 case in March 2020, we show that the pandemic increased the incidence and the value of discretionary contracts, especially in places that have traditionally had high levels of corruption. Moreover, we show that in these places, contracts signed during the emergency are more likely to have cost overruns, be awarded to campaign donors, and exhibit implementation inefficiencies.

\footnotetext{
${ }^{1}$ Examples include Argentina, Australia, Brazil, Canada, Chile, Colombia, France, Germany, Hungary, Israel and New Zealand. To track emergency legislation around the world see: https://www.lexology.com/library/detail.aspx?g=d75c6657-a3f7-4312-b341-7ba8da835fd8 (last accessed on May 2, 2021).

${ }^{2}$ However, under certain circumstances, more discretion can in fact reduce corruption and improve efficiency (Coviello et al., 2018; Duflo et al., 2018; Bandiera et al., 2009, 2020).
} 
Our identification strategy leverages on weekly longitudinal variation across the country's roughly 1,100 municipalities, exploiting the timing of the first detected case of COVID-19 in the country, as well as the cross-sectional variation provided by the baseline probability that a municipality is corrupt. We estimate the latter using an ensemble model that aggregates the corruption predictions of four canonical machine learning algorithms, trained on almost 150 municipality-level characteristics to predict observed cases of corruption prosecutions from 2008 to 2015 .

After the outbreak of COVID-19 in Colombia, places that rank higher on our predicted baseline corruption scale differentially increase the use of discretionary contracts, which are awarded using a direct selection procedure and allow for no competition whatsoever among bidders. The effect is economically large: a one-standard-deviation increase in the predicted baseline probability of corruption increases the probability of awarding a discretionary contract (the average value of a discretionary contract) by $3.4 \%(7.5 \%)$ relative to the preCOVID-19 period weekly mean. The effect is larger for contracts that procure crisis-related items such as food and medical supplies (a 13\% increase relative to the mean). Moreover, the differential effect of the outbreak on discretionary spending in corrupt municipalities is substantially larger after the government declared a state of emergency that enabled local governments to avoid competitive procurement processes.

Importantly, we control for municipality and week fixed effects throughout, as well as the interaction of the latter with baseline levels of population, population density, and a poverty index, which indirectly capture the latent municipal demand for public procurement to face the crisis. Moreover, our results remain unchanged if we control for the spread of the disease across the country. This allows us to rule out the idea that the most corrupt places were more affected by the disease, and accordingly, had to adapt their procurement strategies more intensively than their less corrupt counterparts. Our results are also robust to controlling for municipalities' access to ports and markets, thus suggesting that the results are not driven by corrupt places facing more difficulties and higher prices in the acquisition of crisis-related items. Finally, the main findings are substantively the same if instead of 
using our predicted baseline corruption measure as the treatment variable, we use official transparency and institutional capacity indices.

To be sure, while compelling, our quantitative evidence is only suggestive about the corruption effects of the pandemic. Because of its illegal nature, objectively measuring corruption is challenging (Olken, 2007; Olken and Pande, 2012; Fisman, 2001). We posit that waste and corruption are very likely in this setting because: i) As mentioned, more discretionary and less competitive procurement often generate graft opportunities; ii) We show that in places that rank higher on our corruption scale, contracts signed amid the emergency are more likely to receive cost overrun alerts from the Office of the Comptroller General, be awarded to campaign donors, and exhibit time and budget extensions. In turn, these inefficiencies are highly correlated with the incidence of corruption (Gallego et al., 2020); iii) We discuss anecdotal evidence in section 2 that provides strong support to our interpretation that procurement rules relaxations in response to the crisis have led to more corruption.

This paper contributes to the literature studying the governance challenges imposed by episodes of crisis and catastrophic events, such as wars (Querubin and Snyder, 2013), disasters (Leeson and Sobel, 2008), and epidemics (Khemani, 2020), and in particular, on how these events relate to and affect political outcomes (Fluckiger et al., 2019; Bol et al., 2020; Campante et al., 2020; Amat et al., 2020; Daniele et al., 2020; Maffioli, 2020). We contribute to this literature by showing that public health crises may affect bureaucratic performance and the quality of government spending, by increasing inefficiency and corruption, which can arguably make recovery slower (Best et al., 2019; Bandiera et al., 2020).

Natural disasters create resource windfalls that may trigger corruption and fraud (Leeson and Sobel, 2008; Nikolova and Marinov, 2017). Catastrophic events imply the mobilization of resources in the form of relief, which may be strategically appropriated by political actors (Garret and Sobel, 2003; Gasper and Reeves, 2011; Gallego, 2018). Alternatively, austerity may decrease corruption by reducing public expenditure (Daniele and Giommoni, 2021). We delve deeper into the channels explaining inefficiency and corruption amid a catastrophe by showing how relief spending differentially changes as a function of historical corruption. 
Moreover, we contribute to this literature by empirically documenting a novel mechanism: After a catastrophe, waste and corruption can be exacerbated because public procurement rules need to be relaxed, which in turn can make the cure (spending) worse than the disease.

\section{Context}

The first detected case of COVID-19 in Colombia was announced on March 6th, 2020, and by the end of April of that year almost 6,000 people had tested positive and almost 300 had officially died from the disease. Panel A of Figure A2 in the Appendix reports the temporal evolution of cases in Colombia shortly after the outbreak of COVID-19. On March 17, President Iván Duque appealed to article 215 of the Constitution to declare an "economic and social emergency", which allowed the executive to issue emergency decrees. In one such decrees, the National Public Procurement Agency allowed contracting entities (including local governments) to invoke instances of manifest urgency to speed up procurement when necessary. This entitled officials to directly select contractors without any previous bidding stage in order to expedite the procurement of goods and services considered necessary to face the emergency. ${ }^{3}$

A few weeks after the state of emergency was invoked, Colombia's control agenciesthe Comptroller General, the Inspector General, and the Attorney General-revealed that several local and regional governments were taking advantage of the situation by likely engaging in corruption. These organization released a list of of mayors and governors who had awarded suspicious contracts, in which over costs were apparent. For instance, the Office of the Comptroller General found out that executive authorities in the town of La Palma had bought crisis-related items with price premiums up to $330 \%,{ }^{4}$ and in Arauca food items were bought at prices over five times the market value. ${ }^{5}$ The Colombian independent news ${ }^{3}$ See CCE's statement here:

https://www.colombiacompra.gov.co/sites/cce_public/files/cce_documentos/comunicado_covid_19.pdf (last accessed May 12th, 2020).

${ }^{4}$ See $\quad$ https://www.pulzo.com/nacion/cuarentena-alcalde-palma-explica-sobrecostos-contrato-mercadosPP877697 (last accessed May 11th, 2020).

${ }^{5} \mathrm{See} \quad$ https://forbes.co/2020/04/08/actualidad/contralor-denuncia-sobrecostos-de-80-000-millones-enayudas-por-covid-19-en-el-pais/ (last accessed May 11th, 2020). 
website, La Silla Vacía, studied a sample of 48 contracts awarded in 17 departments in the midst of the emergency and found overprices in more than $40 \%$ of the contracts analyzed. ${ }^{6}$

\section{DATA}

3.1. Public procurement. Public procurement data comes from the Sistema Electrónico para la Contratación Pública (SECOP), a web-based platform established by the Colombian government to digitize transactions held by public entities in the country. The platform details more than 10 million contracts from national and subnational-level public entities. ${ }^{7}$ For this analysis, we focus on contracts held by local-level governments from January 1 to the end of April 2020, covering 357,875 contracts with a total value of US\$ 4.5 billion. ${ }^{8}$

Contract-level information includes the contract's initial value, approval date and duration, a textual description of the contract's purpose, indicators of time or budget extensions, the nature of the contracting agency, and the type of process that was used to select the contractor. The latter includes public tenders, selection based on the qualification of merits, auctions, special regime, minimum-value, and direct selection. Importantly, the direct selection procedure is the least competitive mechanism, and its use is legally restricted to special cases, including situations of manifest urgency caused by particular events such as natural disasters. In turn, the textual description of each contract's purpose allows us to use text-analysis techniques to identify which contracts correspond to crisis-related spending. In particular, using a dictionary method, we identify all contracts related to the procurement of food and health-related goods and services. ${ }^{9}$

\footnotetext{
${ }^{6}$ See https://lasillavacia.com/plata-mas-48-contratos-mercados-se-habrian-alimentado-68-mil-familias-76388 (last accessed July 25th, 2020). Departments are equivalent to U.S. states.

${ }^{7}$ See https://www.datos.gov.co/Gastos-Gubernamentales/SECOP-Integrado/rpmr-utcd (last accessed May 12th, 2020).

${ }^{8}$ Our sample period is limited by the fact that, at the end of April, anticorruption agencies in Colombia announced the creation of a front to combat this phenomenon. However, as we show in section 5, our findings are robust to studying a longer period.

${ }^{9}$ For the food category we used the Spanish words "alimentos", "víveres", "comida", "mercados", "kits", while for health-related procurement, we used the words "médico", "salud", "medicamentos", "hospitalización", "farmacia". The presence of any of these terms in the short description of the contract implied its inclusion in the corresponding category.
} 
We thus have access to fine-grained information on public spending at the municipalityweek level that allows us to confidently track whether a specific municipality used the direct selection method (and for what value) and if such a contract corresponded to the procurement of a crisis-related good or service. Panels B and C of Figure A2 in the Appendix present the evolution of discretionary contracts - i.e. those awarded through the direct selection method - as a share of the sum of discretionary and competitive contracts, respectively for the total number of contracts and the amount awarded by these. ${ }^{10}$

3.2. Corruption. Measuring corruption is challenging (Olken, 2007; Olken and Pande, 2012). More so measuring corruption for all the districts of a particular country. Rather than relying on perceptions of citizens or key actors - a common approach to measure corruption championed by international organizations - we follow Gallego et al. (2020) and Colonnelli et al. (2020) and use a machine learning approach to predict corruption based on factual corruption detections and observable characteristics of municipalities.

Using information from the Office of the Inspector General of Colombia and originally collected by Martinez (2019), we construct a dummy variable indicating if the mayor of each municipality was prosecuted by this anticorruption agency in the 2008-2011 or 2012-2015 mayoral periods. ${ }^{11}$ We define this measure as our outcome variable and combine it with 147 municipal characteristics to train several machine learning models: random forest, gradient boosting machine, lasso, and neural network. We ensemble these using Polley et al. (2011)'s super learner approach to construct a municipal-level risk score in each of the two periods. We use a random $70 \%$ of our dataset to train the models, and the remaining $30 \%$ to test their performance. We use a 5-fold, 10-time repeated cross-validation procedure to train our models and choose the optimal combination of parameters.

We asses the predictive performance of our models in the testing set using conventional metrics, such as the Area Under the ROC curve (AUC) and the accuracy. Overall, our

\footnotetext{
${ }^{10}$ We define 'competitive' contracts as those that are awarded using public tenders, auctions, selection based on merits, or a special regime, as they imply potential competition between two or more bidders.

${ }^{11}$ These prosecutions are carried out for violations by public officials of the disciplinary code. Consequently, this variable should be understood as a broad measure of corruption.
} 
ensemble model achieves a high level of performance, at an accuracy of 0.84 and a AUC of 0.71. Given these numbers, we proceed to construct the corresponding predicted values for each municipality-period, which indicate the probability of being classified as corrupt. The final score for each municipality is the average of the two probabilities, one for each period. Note that the correlation between the probabilities of each period is quite high $(0.7)$, which suggests that municipal corruption may be quite persistent over time.

This index differs from municipal corruption rankings based on observed corruption cases because it enables a highly precise detection of instances of corruption even in cases where watchdog agencies have not detected it. Thus, we use this index throughout as our preferred measure of corrution. However, our results are robust to using alternative transparency measures, issued by state agencies and based on observed behavior. In Appendix A we describe in more detail how we constructed our predicted corruption measure. Figure A1 maps the baseline geographic distribution of predicted corruption in Colombia, according to our model.

3.3. Other Variables. Other variables used in the analysis include the distance from each municipality to the departmental capital and to the nearest port, the longitudinal spread of COVID-19 during our sample period, transparency indices such as the Open Government Index (IGA by its Spanish acronym) -computed by the Inspector General- and the Integral Development Index (IDI) - constructed by the National Planning Department- and data on

cost overrun alerts (from the Office of the Comptroller General) and on campaign donors (from the National Electoral Council). Table A1 in the Appendix reports the descriptive statistics.

\section{EMPIRICAL STRATEGY}

4.1. Main specification. Our identification strategy exploits the timing of the first detected case of COVID-19 in Colombia (March 6th, 2020), as well as the cross-sectional variation provided by the baseline probability of a municipality being corrupt. More formally, using the subindex $m$ to denote municipalities and $t$ to denote weeks, we estimate the 
following difference-in-differences model:

$$
y_{m t}=\alpha_{m}+\lambda_{t}+\beta\left(\text { Post Outbreak }_{t} \times \text { Corrupt }_{m}\right)+\sum_{c \in X_{m}} \gamma^{\prime}\left(c \times \lambda_{t}\right)+\epsilon_{m t}
$$

where $y_{m t}$ are different measures of public procurement in municipality $m$ in week $t$; Corrupt $_{m}$ is a standardized measure of the predicted probability of corruption described in Section 3.2; Post Outbreak $_{t}$ is a dummy that takes the value one after March 6th, 2020; and $X_{m}$ is a set of municipality-level characteristics measured in 2019 that include total population, population density, and a poverty index. We interact these characteristics with the week fixed effects, $\lambda_{t}$, to allow for differential flexible trends parametrized by these municipality features. We also include municipality fixed effects, $\alpha_{m}$, that control for any observed or unobserved municipal-level time invariant heterogeneity. In turn, the non-interacted week dummies control for any time shock that affects simultaneously all the municipalities on the same week. Finally, $\epsilon_{m t}$ is the error term. Given that our treatment variable, Corrupt, is the result from the predicted values of a previously-estimated model, we estimate wild bootstrap standard errors that are clustered at the municipality level.

Our coefficient of interest, $\beta$, captures the average differential change in public procurementrelated outcome of interest,before and after the outbreak of COVID-19 in municipalities with a high estimated baseline probability of corruption relative to municipalities with a low estimated probability. In order to measure the use of discretionary contracts, for the outcome $y_{m t}$ we focus on a dummy variable indicating whether a contract was awarded using the direct selection procedure in municipality $m$ and in week $t$, and the natural log of the average amount of money awarded through this procedure. We also focus on discretionary contracts associated to crisis-related spending, in particular to procure food and health-related services and supplies.

4.2. Identifying assumption. The main assumption behind our empirical model is that in the absence of the outbreak of COVID-19, the usage of discretionary public procurement contracts in municipalities with a high estimated baseline probability of corruption would have followed a similar trajectory to the usage of discretionary public procurement contracts 
in municipalities with a low estimated probability. The validity of this "parallel trends" assumption can be partially assessed by estimating the following non-parametric regression:

$$
y_{m t}=\alpha_{m}+\lambda_{t}+\sum_{j \in J} \beta_{j}\left(\text { Corrupt }_{m} \times \delta_{t}\right)+\sum_{c \in X_{m}} \gamma^{\prime}\left(c \times \lambda_{t}\right)+\varepsilon_{m t}
$$

where $J$ includes all weeks in our sample except from the week before the first COVID-19 case in Colombia. Therefore, the parameters $\beta_{j}$ can be interpreted as the differential usage of, for example, discretionary public procurement contracts in municipalities with a high predicted probability of corruption relative to municipalities with a low probability, in week $j$, relative to the week prior to the first detected COVID-19 case in the country.

\section{RESUlts}

5.1. Corruption and Discretionary Contracts. Table 1 presents the main results from specification (4.1). The dependent variable in Columns 1 to 3 is the indicator of that at least one discretionary contract was awarded in municipality $m$ and week $t$. In Columns 5 to 7 we focus on the $(\log )$ value of discretionary contracts. We find that, after the first COVID-19 case in Colombia, there is a differential increase in the probability of using a discretionary contract in municipalities with higher predicted baseline probability of corruption. Focusing on Column 1, a one-standard-deviation increase in the predicted probability of corruption increases the probability of issuing a discretionary contract in 2.5 percentage points, which represents an increase of $3.4 \%$ with respect to the average in the pre-COVID-19 period. Moreover, we find that the average value of a contract increased by $7.5 \%$ (see Column 5 ). ${ }^{12}$ In addition, Columns 2 and 6 control for the municipal prevalence of the disease by including the number of COVID-19 cases. Controlling for the prevalence of the virus is arguably a 'bad control', but we still do so to make sure that our results are explained by the proclivity of engaging in corruption and not by the severity of the disease. The point estimates are largely robust to this control, suggesting that the intensity of the COVID-19 infection is not

\footnotetext{
${ }^{12}$ Table A2 in the Appendix shows that these results are robust to not including municipality controls, or to their inclusion one at a time.
} 
a likely channel. ${ }^{13}$ Moreover, to test whether our results are explained by municipalities with a higher probability of corruption also finding it more difficult to access supplies, Columns 3 and 7 control for market access by including the distance of each municipality to the nearest port and the department capital interacted with the week fixed effects. We do not find support for this alternative story either.

Finally, in columns 5, 6, 11, and 12 of Table A2, we control for the political affiliation of each mayor, which may be correlated with corruption. For instance, it could be the case that, in times of crisis, the national government is less strict in the use of discretionary spending in municipalities ruled by mayors affiliated to the same political party. Our results are robust to the inclusion of these controls too.

\subsection{Additional Robustness Tests and Alternative Specifications. Table 2 reports}

additional robustness tests. First, Columns 1 and 2 report the results of a placebo exercise in which we estimate our main model — equation (4.1)—for the same weeks but over 2019. The null coefficients found in this case show that our results are not driven by seasonal patterns. Second, Columns 3 to 6 assess the robustness of our inference. Columns 3 and 4 follow Conley (1999) and Conley (2016) and control for cross-sectional dependence and first order time dependence in the error term. Columns 5 and 6 follow Bertrand et al. (2004) and collapse the data before and after the first COVID-19 case to deal with potential serial correlation in the dependent variable. Our results are robust to both of these corrections. Column 7 shows that the result for the value of contracts is robust if we use a hyperbolic sine transformation, which takes into account the zeros in the dependent variable and keeps the number of observations constant.

Third, in Figure A4, we present the robustness to the exclusion of one department at a time. The coefficients are stable to the exclusion of any department. Consequently, our results are not driven by any particular department, which is important given the role that

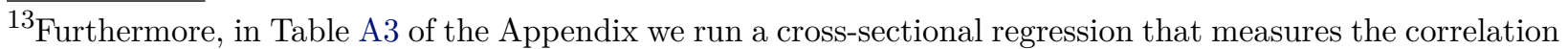
between the number of COVID-19 cases (Column 1) and the number deaths (Column 2), with our corruption index. We do not find any significant association. Moreover, the point estimate of the correlation with the number of COVID-19 deaths (which is arguably the most exogenous of the two measures) is very close to zero.
} 
some parts of Colombia have had in terms of both historical corruption and the spread of the pandemic. Similarly, Tables A4 and A5 in the Appendix show that the results are robust to the presence of outliers, both in the corruption index and in the value of the contracts. ${ }^{14}$ Therefore, the results are not driven by a handful of municipalities either. Finally, Figure A5 plots the distribution of estimates from a randomization inference test, which involves 500 simulations where we randomly assign the estimated values of the predicted probability of corruption across municipalities and estimate the main regression of interest for each outcome. For both variables, the probability of finding an estimate as the one presented in Table 1 is below 1\%, showing that our results are unlikely to be driven by pure chance.

Furthermore, instead of our corruption index, we use two alternative official cross-sectional measures of transparency and institutional capacity, at the municipality level. ${ }^{15}$ We use the Open Government Index (IGA for its Spanish acronym), which was developed by the Office of the Inspector General to officially measure transparency, ${ }^{16}$ and the Integral Development Index (IDI for its Spanish acronym), constructed by the National Planning Department, to measure institutional capacity. ${ }^{17}$ Higher IGA and IDI values, on a scale of 0 to 100 , indicate higher levels of transparency and institutional capacity, respectively. We interact the 2016 IGA and 2017 IDI measures (the last years for which each one is available) with the post-COVID time indicator, to determine if there is a differential change in the use of discretionary contracts in municipalities with high levels of transparency and institutional capacity. Columns 8 and 9 (10 and 11) of Table 2 show that a one standard deviation increase in the IGA (IDI) index implies a reduction of 3.1 (2.7) percentage points in the probability of issuing a discretionary contract and a decrease of $5.4 \%(4.6 \%)$ in the average value of this type of contracts. These findings imply that our main result does not depend exclusively on the measure of corruption that we built using machine learning techniques.

\footnotetext{
${ }^{14}$ We winsorize at the $1 \%, 2.5 \%$, and $5 \%$ levels these two variables and re-estimate the main models based on (4.1).

${ }^{15}$ In other specifications, available upon request, we use the average observed corruption cases (instead of the machine-learning prediction) as the treatment variable. The results are quite similar to those presented in Table 1.

${ }^{16}$ See https://www.procuraduria.gov.co/portal/que_es_IGA.page (last accessed July 21, 2020).

${ }^{17}$ See https://www.dnp.gov.co/programas/desarrollo-territorial/Estudios-Territoriales/Indicadores-yMediciones/Paginas/desempeno-integral.aspx (last accessed July 21, 2020).
} 
Finally, we corroborate that our findings are not driven by the choice of the sample period, which ends on the week of April 27, 2020. To shed light on this, in Table A8 of the Appendix we present the results of models in which we extend the end date in 2, 4, 6, 8, and 10 weeks, respectively. In all cases, the results remain positive and statistically significant for our two outcome variables of interest.

5.3. Parallel Trends and Dynamics. In Figure 1 (panels A and B), we present the results from equation (4.2). In both panels we find no differential trends in the six weeks before the first COVID-19 case for municipalities with a higher predicted baseline probability of corruption relative to the ones with a lower probability. In fact, the p-values for the F-tests of joint significance of these coefficients are 0.24 and 0.18 , for panels A and B, respectively. Overall, this evidence provides support for the main identifying assumption of our empirical strategy. Intuitively, it is highly unlikely that there would have been any anticipatory effects, since in January and February COVID-19 was still seen as a distant disease that would not have major impacts in Colombia. Figure A3 reports equivalent results for the IGA and IDI, the alternative official measures of transparency and institutional capacity. Moreover, the figures suggest that, in contrast to the estimated (null) effects for the weeks prior to the first COVID-19 case in Colombia, after the arrival of the pandemic there is a differential increase in the usage and value of discretionary public procurement contracts in municipalities with a higher baseline probability of corruption, and lower levels of transparency and institutional capacity. Interestingly, these effects grow over time, suggesting that the effect of the pandemic on contract inefficiency and corruption is persistent.

5.4. Mechanisms. We corroborate this increasing pattern over time in a more parametric way, by splitting the post COVID-19 period into two, taking into account the March 17 presidential decree that enabled municipalities to declare a manifest urgency in order to increase the use of discretionary contracts. In columns 4 and 8 of Table 1, we include a time dummy that takes the value of one for weeks between the first case and the release of the presidential decree (called Post 1), and a second dummy that equals one for weeks after the release of the presidential decree (Post 2). We find that for both of our main 
dependent variables there is a larger and statistically significant effect after the relaxation of the requirements for the usage of discretionary contracts.

We then study whether the pattern encountered for discretionary contracts can be also found for competitive procurement, which limits the scope for graft and was not directly affected by any presidential decree. We find that there is a (marginally) significant decrease in the usage of this type of contracts in municipalities with a higher baseline corruption index after the outbreak of the pandemic, while their average value does not differentially increase in these places (see Table A6 and Figure A6 in the Appendix). This result is important because it suggests that there is no differential increase, after the arrival of the disease, in the citizen demand for public services not related to the emergency.

Moreover, using text analysis, we grouped contracts distinguishing between crisis needs (food and health-related items), versus other contracts. We find that after the first COVID19 case in Colombia municipalities that are one-standard-deviation more likely to be corrupt at baseline experience an increase in the average value of crisis-related contracts of $7 \%$ (see Column 1 of Table 3 and panels $\mathrm{C}$ to $\mathrm{E}$ of Figure 1). Moreover, when we divide the post COVID-19 period into Post 1 and Post 2, the size of the effect doubles to 13\% (Column 2). When we split contracts between food and health-related purchases, we find that most of the effect is driven by a large increase in the value of food-related items in municipalities predicted to be more corrupt at baseline. These results go in line with the evidence which suggests that malfeasance was mainly driven by cost overruns in the acquisition of food relief.

Finally, we corroborate whether the effect of baseline corruption on discretion during the pandemic is exacerbated or attenuated by key political characteristics of municipalities, namely: i) Presence of anticorruption agencies (i.e. number of offices of the Inspector General); ii) Political affinity with the President (i.e. the mayor's party); iii) Presence of the media (i.e. number of radio stations). Table A9 shows that there are robust heterogeneous effects only in the case of the presence of anticorruption authorities, in line with the evidence that suggests that top-down accountability is key to containing this phenomenon (Olken, 2007; Avis et al., 2018). 
5.5. Is it Corruption? At this point, it is natural to ask whether our empirical results necessarily imply that corruption increased due to the pandemic. As we recognized in the introduction to this paper, we do not have a smoking gun allowing us to verify, with an absolute level of certainty, that acts of corruption were in fact committed in Colombian municipalities. In some cases, discretion may simply imply waste and inefficiency. In other cases, it may be even desirable (Decarolis et al., 2020). Nevertheless, in this subsection we present suggestive evidence consistent with the fact that after the outbreak of COVID-19 in Colombia, places with higher levels of baseline corruption showed a greater number of irregularities in public procurement. For this purpose, we use information from judicial investigations carried out during the pandemic by an anti-corruption agency, data on campaign donations in the 2019 local elections, and information from SECOP on contracts that required extensions (in time or money) after being awarded.

First, we had confidential access to the classified information on the cross section of municipalities that, as of June 2020, had received at least one alert for cost overruns during the pandemic from the Office of the Comptroller General, the independent government institution in charge of the fiscal control in the country. Column 1 of Table 4 shows the results of cross-sectional regressions in which we assess the correlation between our estimated baseline corruption measure and the probability of receiving an alert from the Comptroller's Office, controlling for baseline characteristics and department fixed effects. The correlation is positive, statistically significant and large. A one standard deviation increase in the corruption index is associated with a probability of receiving an alert 7.5 percentage points higher, which represents a $63 \%$ increase with respect to the mean for this outcome. Although this evidence is only suggestive and correlational, it indicates that during the pandemic, contracts with cost overruns were mainly awarded in places that have historically been more corrupt according to our measure. ${ }^{18}$

\footnotetext{
${ }^{18}$ In Table A7 of the Appendix we re-estimate the main results dropping from our sample all the municipalities identified by the Office of the Comptroller General as having cost overruns in public procurement. The results are largely unchanged which suggest that our results are not driven by these municipalities and so our predicted baseline corruption index explains the use of discretionary contracts and other inefficiencies in public procurement above and beyond the areas flagged by this control agency.
} 
Next, using information from the National Electoral Council, we identified all natural and legal persons who were campaign donors in the 2019 local elections and who received a contract during 2020. There is an empirical literature that shows that the allocation of contracts to campaign donors is often associated with favoritism (Baranek and Titl, 2020; Baltrunaite, 2020), inefficiency (Mironov and Zhuravskaya, 2016; Ruiz, 2017; Gulzar et al., 2021), and corruption (Fazekas and Cingolani, 2017; Hummel et al., 2019). In fact, Gulzar et al. (2020) show that in Colombia, "donors to mayoral campaigns are typically local business owners seeking to gain preferential treatment in public procurement assignment." Using a differencein-difference specification, Table 4 presents evidence that after the arrival of COVID-19 to the country, the allocation to campaign donors of contracts of any type (Column 2), and of direct contracts (Column 3), increases more in municipalities with higher levels of baseline corruption. ${ }^{19}$ An additional standard deviation in the corruption index increases the probability of awarding any type of contract and a direct contract to a campaign donor in approximately one percentage point.

Finally, we use information provided by SECOP that proxies for the quality of a contract, specifically over costs and time extensions with respect to the original budget and the timeline initially established. These measures are certainly proxies of inefficiency (what Bandiera et al. (2009) call passive waste), and tend to correlate positively with corruption (Bandiera et al., 2009; DalBo et al., 2013; Gallego et al., 2020; Bosio et al., 2020). As before, using a difference-in-difference specification, Columns 4-9 of Table 4 show that, after the arrival of COVID-19, the increase in over costs and time extensions in direct contracts, and to buy food and health-related items, is greater in municipalities with higher baseline corruption. Column 4 (7) shows, for instance, that an additional standard deviation in baseline corruption increases the probability of having a direct contract with over costs (time extensions) in $1.2(2.4)$ percentage points. This is a very large effect, equivalent to $50 \%(92 \%)$ of the mean of the dependent variable. The coefficients are also always significant for contracts to procure food and health-related items.

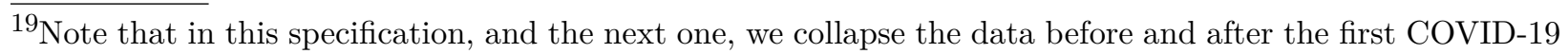
case to deal with the sparsity in the dependent variable.
} 
In sum, although proving waste and corruption is hard, the evidence presented in this section shows that after the arrival of COVID-19 in Colombia, contracts are more likely to have judicially proven cost overruns, to be assigned to campaign donors, and to report over costs and time extensions in places with higher baseline levels of corruption.

\section{Conclusion}

This paper documents that in Colombia the spending rush led by COVID-19 differentially increased more the usage and value of discretionary procurement contracts in places initially more likely to be corrupt. Moreover, we find that in the post-pandemic period, contracts signed in these places are more likely to have judicially-proven cost overruns, be awarded to campaign donors, and exhibit implementation inefficiencies often linked to malfeasance. Our findings have important policy implications. In order to curb the potential negative effects of the relaxation of contracting procedures in terms of waste and graft, top-down accountability tools such as audits - which have proven effective in other contexts (Olken, 2007; Avis et al., 2018) - should accompany the relaxation of contracting rules. More transparency, coupled with technology and data science, could also help reducing inefficiency and corruption. Ultimately, in these contexts, preventing corruption may well save lives.

\section{REFERENCES}

Acemoglu, D., V. Chernozhukov, I. Werning, And M. Whinston (2020): "A Multi-Risk SIR Model with Optimally Targeted Lockdown," Mimeo.

Amat, F., A. Falco-Gimeno, A. Arenas, and J. Muñoz (2020): "Pandemics meet democracy. Experimental evidence from the COVID-19 crisis in Spain," Mimeo.

Avis, E., C. Ferraz, and F. Finan (2018): "Do Government Audits Reduce Corruption? Estimating the Impacts of Exposing Corrupt Politicians," Journal of Political Economy, 126, 1912-1964.

Baltrunaite, A. (2020): "Political contributions and public procurement: evidence from Lithuania," Journal of the European Economic Association, 18, 541-582.

Baltrunaite, A., C. Giorgiantonio, S. Mocetti, and T. Orlando (2018): "Discretion and supplier selection in public procurement," Bank of Italy Temi di Discussione (Working Paper) No, 1178. 
Bandiera, O., M. Best, A. Khan, and A. Prat (2020): "The Allocation of Authority in Organizations: A Field Experiment with Bureaucrats," NBER Working Paper no. 26733. Bandiera, O., A. Prat, and T. Valletti (2009): "Active and Passive Waste in Government Spending: Evidence from a Policy Experiment," American Economic Review, 99, 1278-1308.

BaraneK, B. And V. Tith (2020): "The cost of favoritism in public procurement," Working Paper.

Bertrand, M., E. Duflo, and S. Mullainathan (2004): "How much should we trust differences-in-differences estimates?" The Quarterly journal of economics, 119, 249-275.

Best, M., J. HJort, and D. Szakonyi (2019): "Individuals and Organizations as Sources of State Effectiveness," NBER Working Paper no. 23350.

Bol, D., M. Giani, A. Blais, And P. Loewen (2020): "The effect of COVID-19 lockdowns on political support: Some good news for democracy?" European Journal of Political Research, 60, 497-505.

Bosio, E., S. Djankov, E. Glaeser, and A. Shleifer (2020): "Public Procurement in Law and Practice," NBER Working Paper no. 27188.

Campante, F., E. Depetris-Chauvin, and R. Durante (2020): "The Virus of Fear: The Political Impact of Ebola in the U.S." Mimeo.

Colonnelli, E., J. Gallego, And M. Prem (2020): "What Predicts Corruption?" Mimeo.

Conley, T. G. (1999): "GMM estimation with cross sectional dependence," Journal of Econometrics, 92, 1-45.

(2016): Spatial Econometrics, London: Palgrave Macmillan UK, 1-9.

Coviello, D., A. Guglielmo, and G. Spagnolo (2018): "The effect of discretion on procurement performance," Management Science, 64, 715-738.

DalBo, E., F. Finan, And M. Rossi (2013): "Strengthening State Capabilities: The Role of Financial Incentives in the Call to Public Service," Quarterly Journal of Economics, 128, 1169-1218.

Daniele, G. and T. Giommoni (2021): "Corruption under austerity," .

Daniele, G., A. Martinangeli, F. Passarelli, W. Sas, and L. Windsteiger (2020): "Wind of Change? Experimental Survey Evidence on the COVID-19 Shock and Socio-Political Attitudes in Europe," Mimeo.

De Michele, R. And J. Cruz (2020): "How Transparency Can Save Lives in the Coronavirus Crisis," Americas Quarterly.

Decarolis, F., R. J. Fisman, P. Pinotti, And S. Vannutelli (2020): "Rules, Discretion, and Corruption in Procurement: Evidence from Italian Government Contracting," 
Duflo, E., M. Greenstone, R. Pande, and N. Ryan (2018): "The value of regulatory discretion: Estimates from environmental inspections in India," Econometrica, 86, 21232160.

Fazekas, M. And L. Cingolani (2017): "Breaking the cycle? How (not) to use political finance regulations to counter public procurement corruption," The Slavonic and East European Review, 95, 76-116.

Fisman, R. (2001): "Estimating the value of political connections," American economic review, 91, 1095-1102.

Fluckiger, M., M. Ludwig, And A. Onder (2019): "Ebola and state legitimacy," Economic Journal, 129, 2064-2089.

Gallego, J. (2018): "Natural Disasters and Clientelism: The Case of Floods and Landslides in Colombia," Electoral Studies, 55, 73-88.

Gallego, J., G. Rivero, and J. Martinez (2020): "Preventing Rather than Punishing: An Early Warning Model of Malfeasance in Public Procurement," International Journal of Forecasting, https://doi.org/10.1016/j.ijforecast.2020.06.006.

Garret, T. And R. Sobel (2003): "The Political Economy of FEMA Disaster Payments," Economic Inquiry, 41, 496-509.

Gasper, J. And A. Reeves (2011): "Make It Rain? Retrospection and the Attentive Electorate in the Context of Natural Disasters," American Journal of Political Science, $55,340-355$.

Gulzar, S., M. Rueda, And N. Ruiz (2020): "Do Campaign Contribution Limits Curb the Influence of Money in Politics?" Working Paper.

Gulzar, S., M. R. Rueda, And N. A. Ruiz (2021): "Do Campaign Contribution Limits Curb the Influence of Money in Politics?" American Journal of Political Science.

Hummel, C., J. Gerring, and T. Burt (2019): "Do Political Finance Reforms Reduce Corruption?" British Journal of Political Science, doi:10.1017/S0007123419000358, 1-21.

Kang, K. And R. A. Miller (2017): "Winning by Default: Why is There So Little Competition in Government Procurement?" Unpublished working paper.

Khemani, S. (2020): "An Opportunity to Build Legitimacy and Trust in Public Institutions in the Time of COVID-19," World Bank Research and Policy Brief.

Leeson, P. And R. Sobel (2008): "Weathering Corruption," The Journal of Law and Economics, 51, 667-681.

Ludvigson, S., S. MA, And S. NG (2020): "Covid19 and the Macroeconomic Effects of Costly Disasters," Mimeo.

Maffioli, E. (2020): "The Political Economy of Health Epidemics: Evidence from the Ebola Outbreak," Mimeo. 
Martinez, L. (2019): "Sources of Revenue and Government Performance: Evidence from Colombia," Mimeo.

Mironov, M. and E. Zhuravskaya (2016): "Corruption in Procurement and the Political Cycle in Tunneling: Evidence from Financial Transactions Data," American Economic Journal: Economic Policy, 8, 287-321.

Nikolova, E. And N. Marinov (2017): "Do Public Fund Windfalls Increase Corruption? Evidence From a Natural Disaster," Comparative Political Studies, 50, 1455-1488.

Olken, B. (2007): "Monitoring Corruption: Evidence from a Field Experiment in Indonesia," Journal of Political Economy, 115, 200-249.

Olken, B. And R. Pande (2012): "Corruption in Developing Countries," Annual Review of Economics, 4, 479-509.

Palguta, J. And F. Pertold (2017): "Manipulation of Procurement Contracts: Evidence from the Introduction of Discretionary Thresholds," American Economic Journal: Economic Policy, 9, 293-315.

Polley, E. C., S. Rose, And M. J. Van Der LaAn (2011): "Super learning," in Targeted Learning, Springer, 43-66.

Querubin, P. And J. Snyder (2013): "The Control of Politicians in Normal Times and Times of Crisis: Wealth Accumulation by U.S. Congressmen, 1850-1880," Quarterly Journal of Political Science, 8, 409-450.

Ruiz, N. A. (2017): "The Power of Money. The Consequences of Electing a Donor Funded Politician," Unpublished manuscript.

Tran, A. (2011): "Which regulations reduce corruption? Evidence from the internal records of a bribe-paying firm," Journal of Development Economics.

Transparency International (2010): "Handbook of Good Practices: Preventing Corruption in Humanitarian Operations," Tech. rep., Transparency International.

Van der LaAn, M. J., E. C. Polley, And A. E. Hubbard (2007): "Super Learner," Statistical Applications in Genetics and Molecular Biology, 6. 


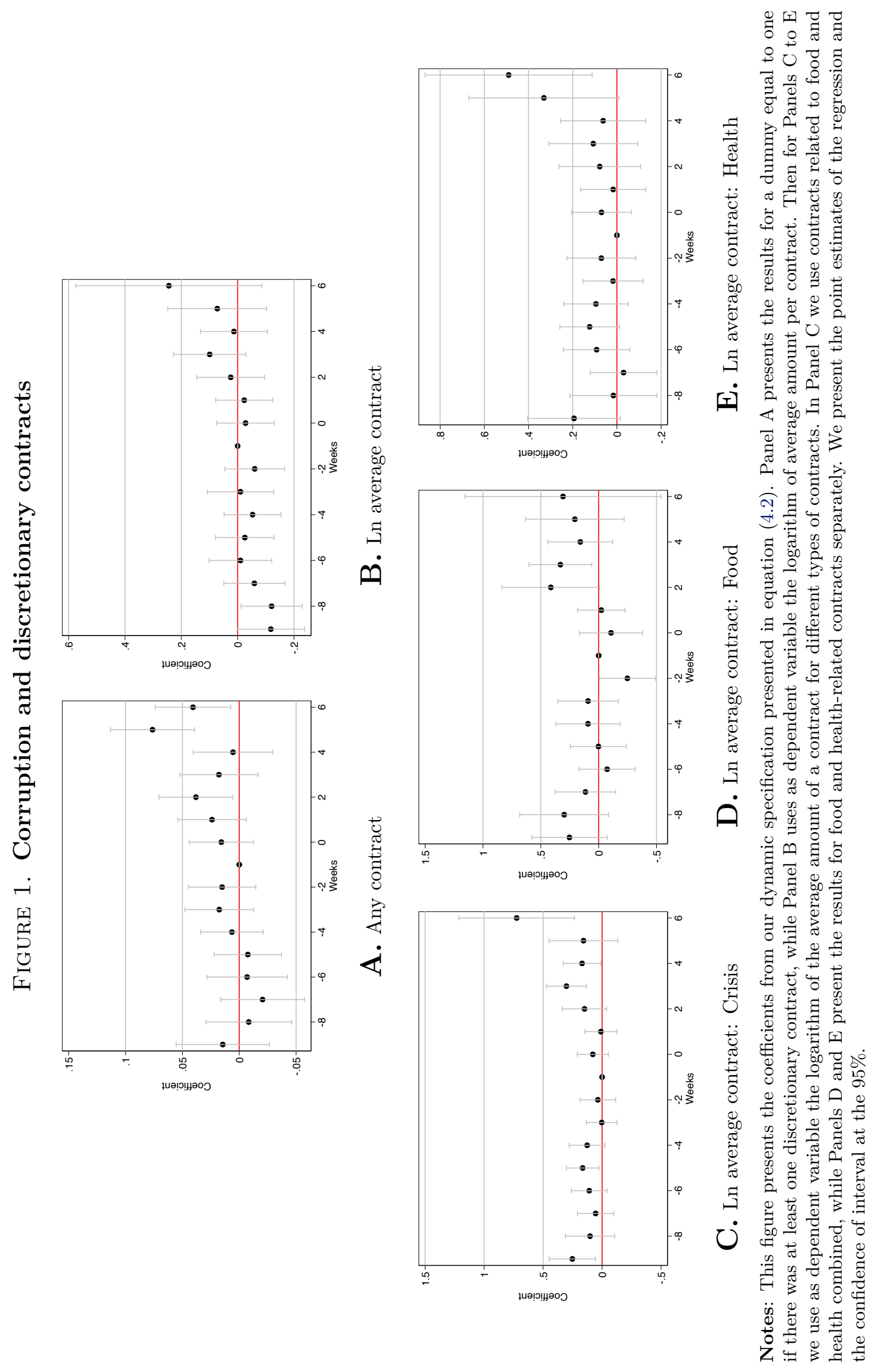




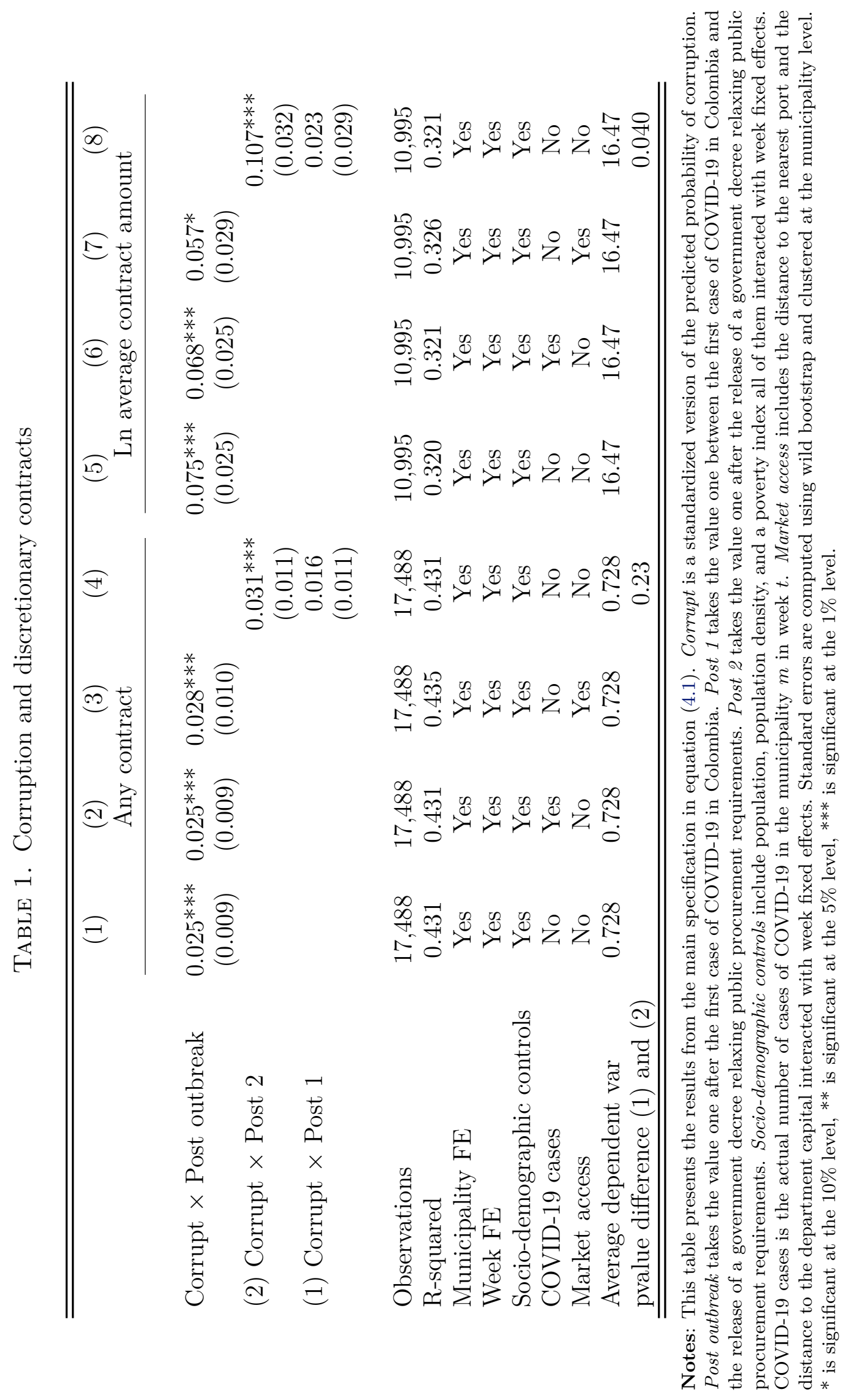




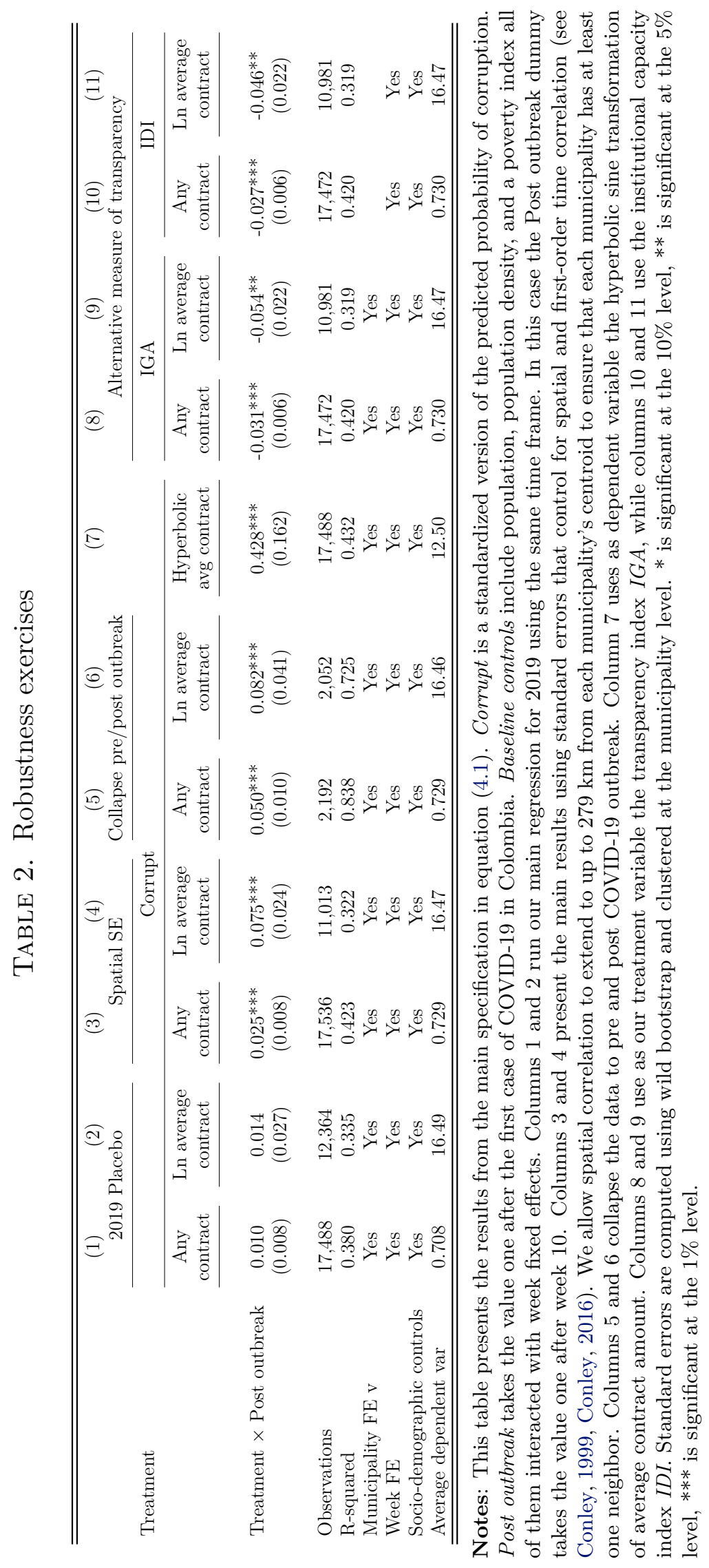


TABLE 3. Corruption and crisis related contracts

\begin{tabular}{|c|c|c|c|c|c|c|}
\hline & (1) & $(2)$ & $(3)$ & (4) & $(5)$ & $(6)$ \\
\hline & \multicolumn{2}{|c|}{ Crisis } & \multicolumn{2}{|c|}{ Food } & \multicolumn{2}{|c|}{ Health } \\
\hline Corrupt $\times$ Post outbreak & $\begin{array}{c}0.073^{*} \\
(0.046)\end{array}$ & & $\begin{array}{l}0.134^{*} \\
(0.087)\end{array}$ & & $\begin{array}{c}0.026 \\
(0.050)\end{array}$ & \\
\hline (1) Corrupt $\times$ Post 2 & & $\begin{array}{c}0.130^{* * *} \\
(0.055)\end{array}$ & & $\begin{array}{c}0.212^{* * *} \\
(0.104)\end{array}$ & & $\begin{array}{c}0.055 \\
(0.063)\end{array}$ \\
\hline (2) Corrupt $\times$ Post 1 & & $\begin{array}{l}-0.044 \\
(0.047)\end{array}$ & & $\begin{array}{l}-0.118 \\
(0.087)\end{array}$ & & $\begin{array}{l}-0.020 \\
(0.050)\end{array}$ \\
\hline Observations & 5,369 & 5,369 & 1,678 & 1,678 & 4,604 & 4,604 \\
\hline R-squared & 0.426 & 0.428 & 0.548 & 0.551 & 0.404 & 0.404 \\
\hline Municipality FE & Yes & Yes & Yes & Yes & Yes & Yes \\
\hline Week FE & Yes & Yes & Yes & Yes & Yes & Yes \\
\hline Socio-demographic & Yes & Yes & Yes & Yes & Yes & Yes \\
\hline Average dependent var & 16.35 & 16.35 & 16.51 & 16.51 & 16.33 & 16.33 \\
\hline pvalue difference (1) and (2) & & 0.000 & & 0.000 & & 0.170 \\
\hline
\end{tabular}

Notes: This table presents the results from the main specification in equation (4.1). The dependent variable is the logarithm of the average value of a contract. Crisis includes food and health related contracts. Corrupt is a standardized version of the predicted probability of corruption. Post outbreak takes the value one after the first case of COVID-19 in Colombia. Post 1 takes the value one between the first case of COVID-19 in Colombia and the release of a government decree relaxing public procurement requirements. Post 2 takes the value one after the release of a government decree relaxing public procurement requirements. Socio-demographic controls include population, population density, and a poverty index all of them interacted with week fixed effects. Standard errors are computed using wild bootstrap and clustered at the municipality level. * is significant at the $10 \%$ level, ** is significant at the $5 \%$ level, $* * *$ is significant at the $1 \%$ level. 


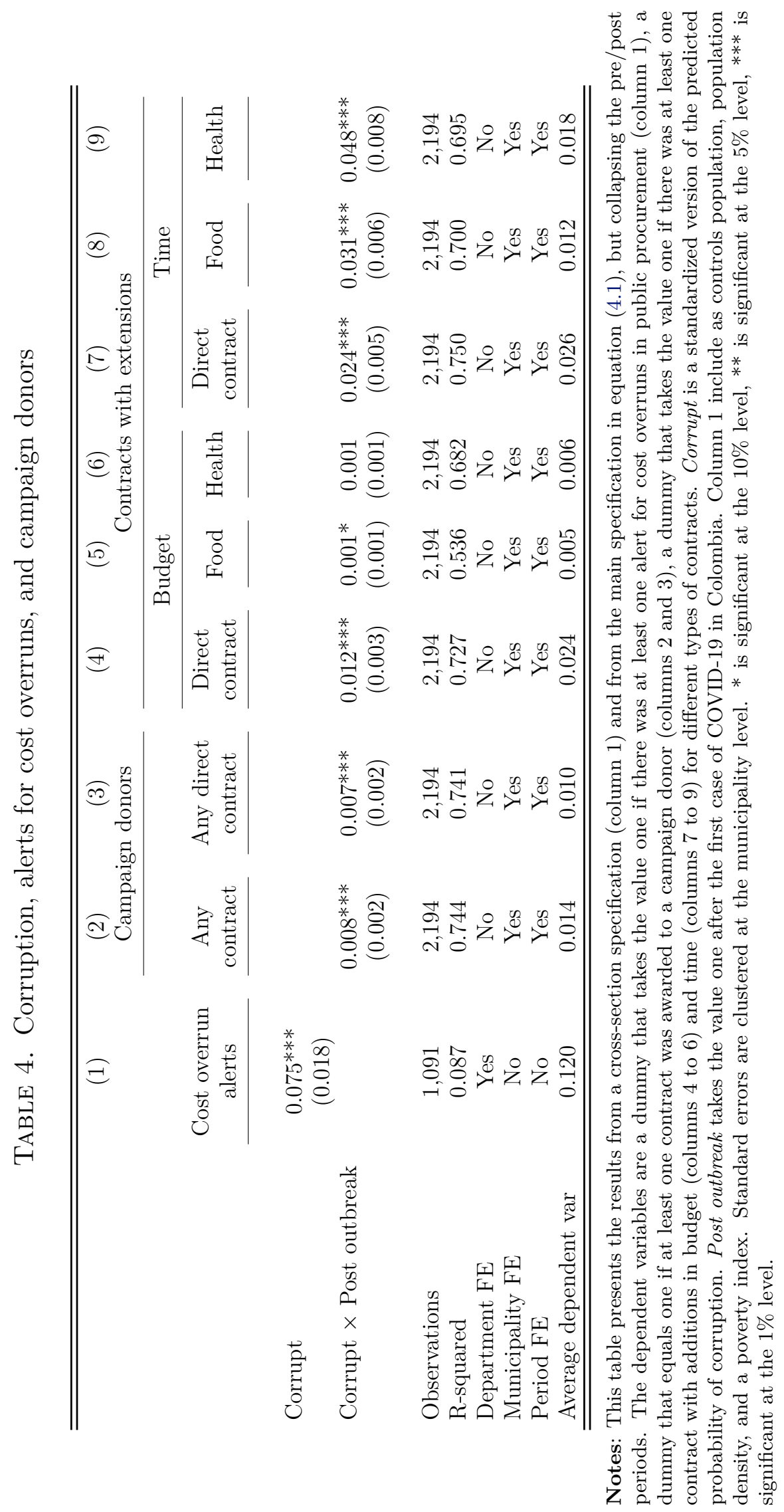




\section{Online Appendix}

\section{Appendix A. Construction of the Municipality Corruption Index}

To construct our predicted baseline corruption measure, we use a total of 147 municipalitylevel predictors. Each variable corresponds to one of the following ten categories: financial sector, conflict, crime, human capital, local politics, public sector, local demographics, economic activity, illegal activity, and natural resources. For the outcome variable used to train the models, we construct a dummy variable indicating if the mayor of each municipality was prosecuted by this anti-corruption agency in the 2008-2011 or 2012-2015 mayoral periods. The information to build this measure comes from the Office of the Inspector General and was collected by Martinez (2019). Using this outcome variable, and the 147 aforementioned predictors, we trained four canonical machine learning models for each period of government. In particular, we trained random forests, gradient boosting machine, neural network, and lasso. The results are not very different if other algorithms are used instead.

In each case, we follow the following steps:

(1) The dataset is divided into a training set consisting of $70 \%$ of the observations and a testing set with the remaining $30 \%$.

(2) 5-fold cross-validation is performed in the training set in order to select the optimal combination of parameters for each algorithm and to train the models.

(3) The previous step is repeated 10 times varying randomly the partitions. Hence, 10 optimal sets of parameters are obtained. The final optimal parameter set is the average of these.

(4) Using this optimal parameters the predictive performance of the models is assessed in the test set that was not used for training purposes.

(5) Finally, individual models are ensambled using the Super Learner procedure (Van der Laan et al., 2007; Polley et al., 2011), in order to stack the individual predictions.

We use ensemble methods to finally construct the corruption measure as it is the case that the combination of different models perform better than their individual components. The models achieve acceptable levels of predictive performance, with a precision of $84 \%$ and an area under the ROC curve (AUC) of 0.71. These final models are used to estimate the level of corruption in each period of government, and the final measure we use is the standardized average of the score obtained by each municipality in these two periods. The correlation between the probabilities of each period is quite high (0.7), which suggests that municipal corruption may be quite persistent over time. This is important for our analysis, because it implies that the predicted probability of corruption until 2015, can be a good proxy for the latent probability of corruption in 2020 . 


\section{Appendix B. Additional Graphs and Tables}

Figure A1. Spatial distribution of corruption

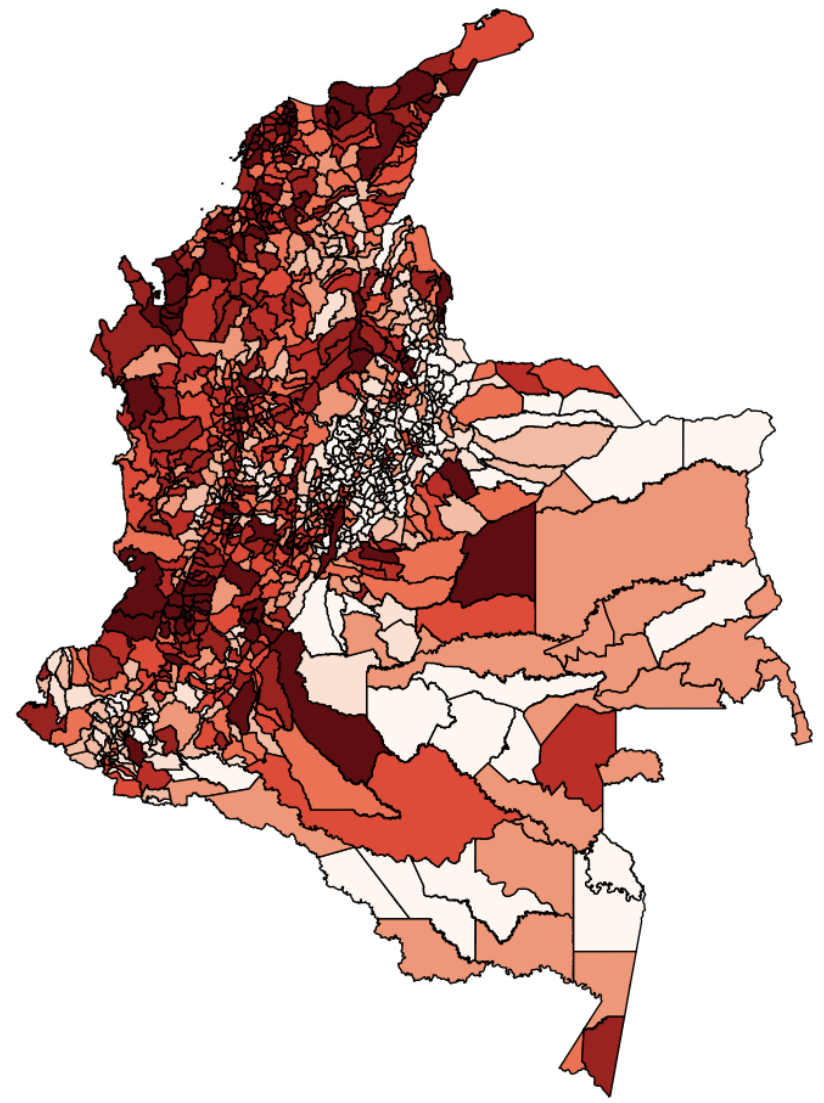

A. Corruption

Notes: This figure presents the spatial distribution of the predicted probability of corruption as discussed in Section 3.2. We divide corruption into deciles, the darker red shows municipalities with higher levels of corruption. 


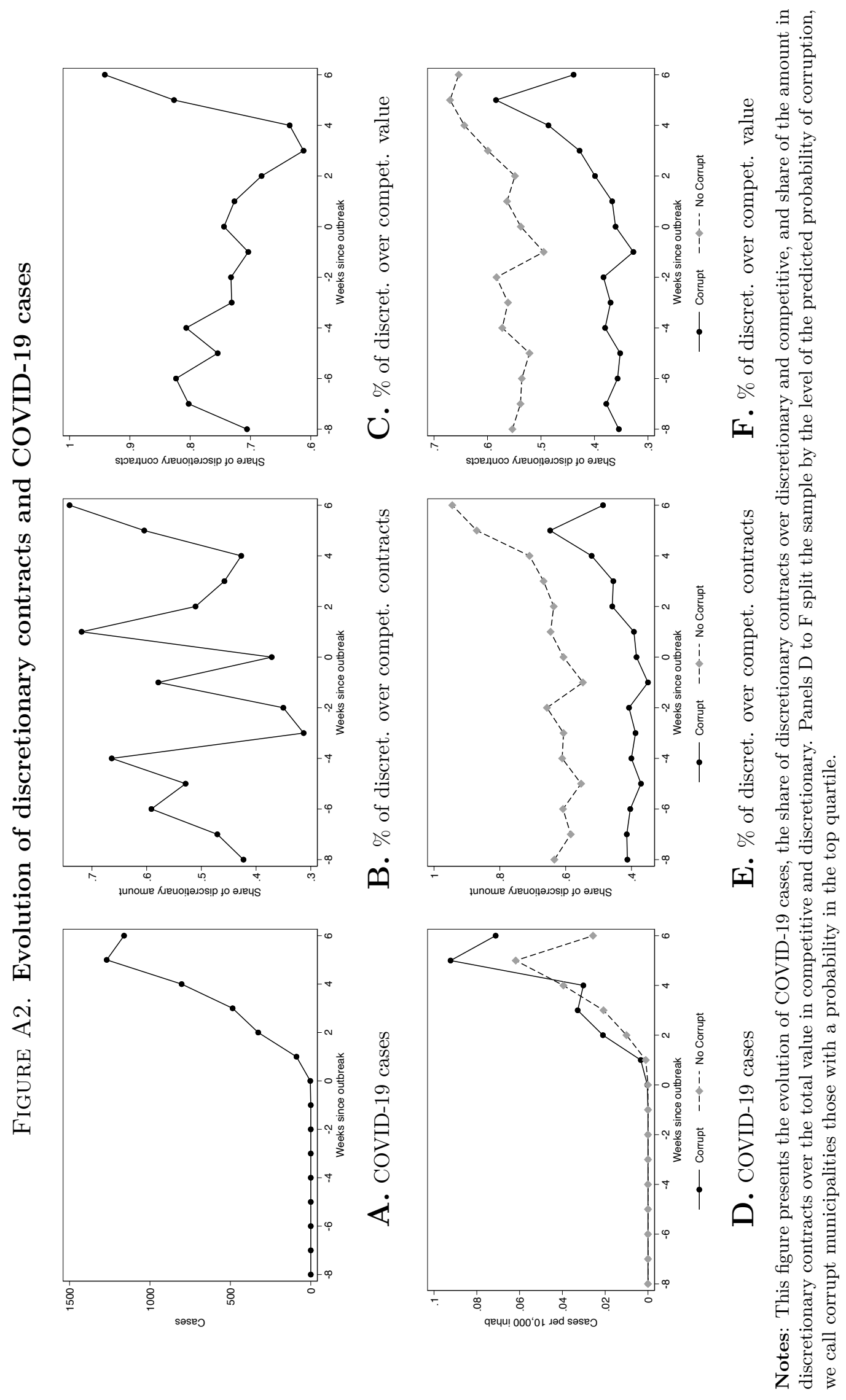




\section{FIGURE A3. Measures of transparency and discretionary contracts}

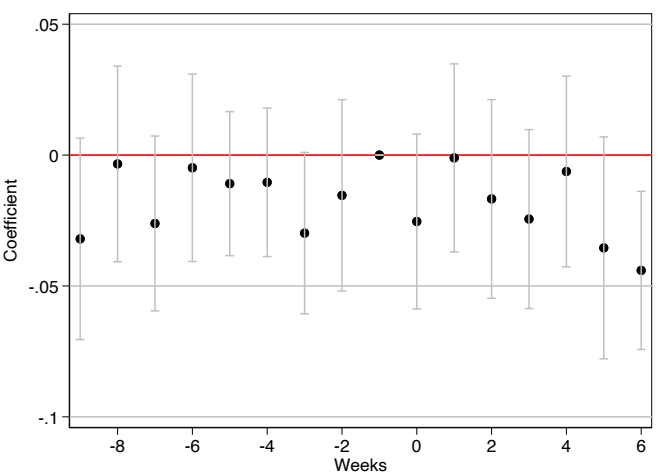

A. IGA-Any contract

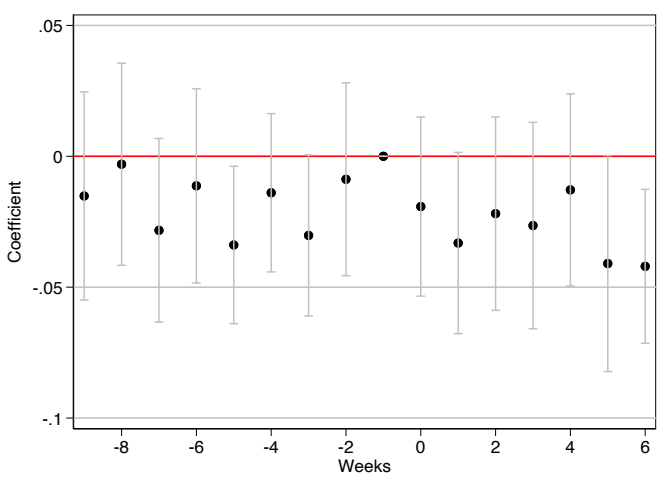

C. IDI-Any contract

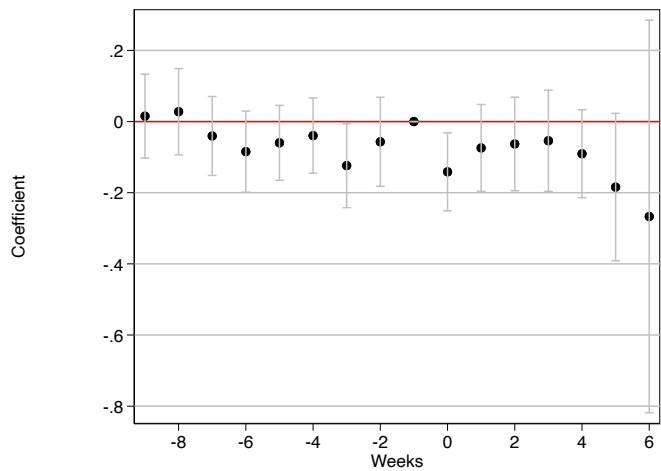

B. IGA-Ln avg amount

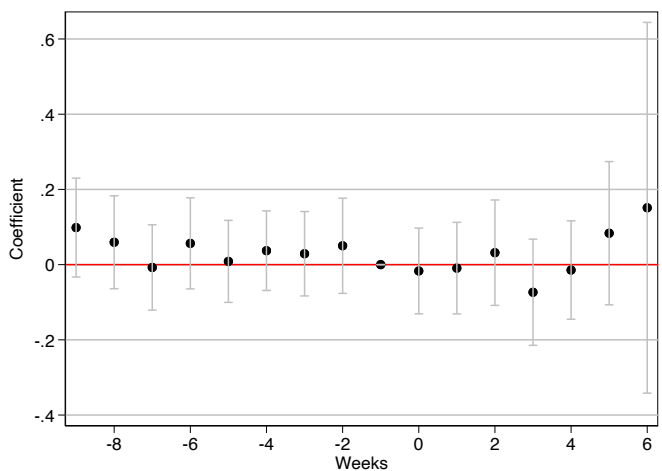

D. IDI-Ln avg amount

Notes: This figure presents the coefficients from our dynamic specification presented in equation (4.2). Panels A and $\mathrm{B}$ use as treatment variable the transparency index IGA, while Panels C and D use as treatment the institutional capacity index IDI. Panels A and C presents the results for a dummy equal to one if there was at least one discretionary contract, while Panels B and D uses as dependent variable the logarithm of average amount per contract. We present the point estimates of the regression and the confidence of interval at the $95 \%$. 
FiguRe A4. Robustness to excluding one department at the time

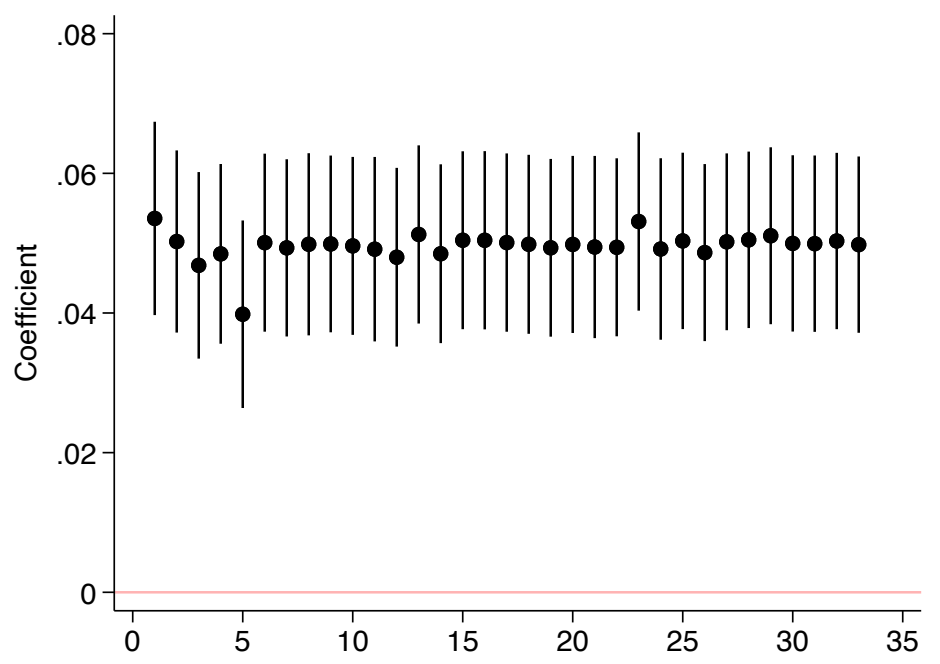

A. Any contract

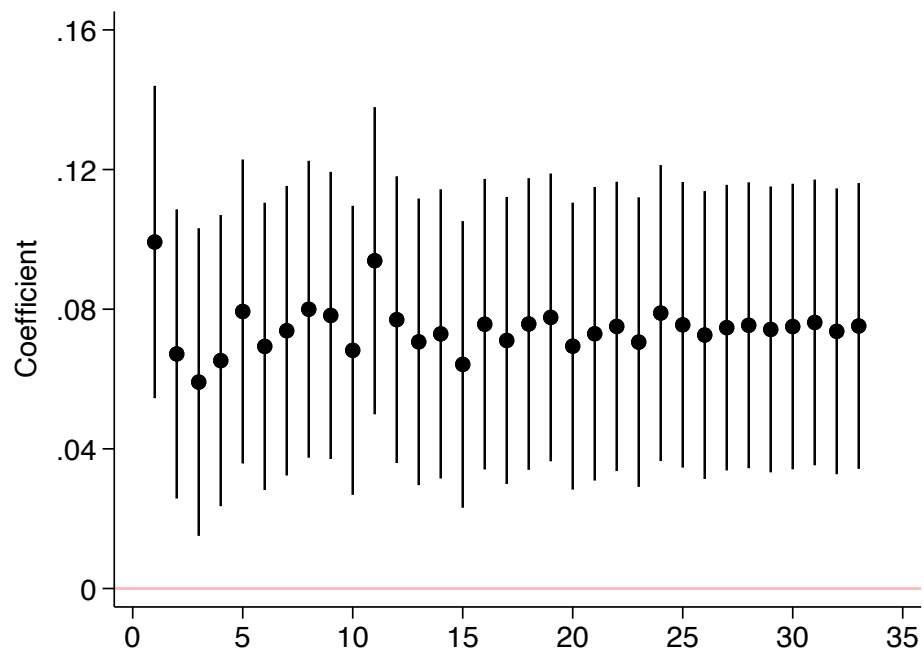

B. Ln average contract

Notes: This figure presents the robustness to excluding one department at the time and estimate the main specification (4.1). We present the point estimates of the regression and the confidence of interval at the $95 \%$. 


\section{FIGURE A5. Randomization inference}

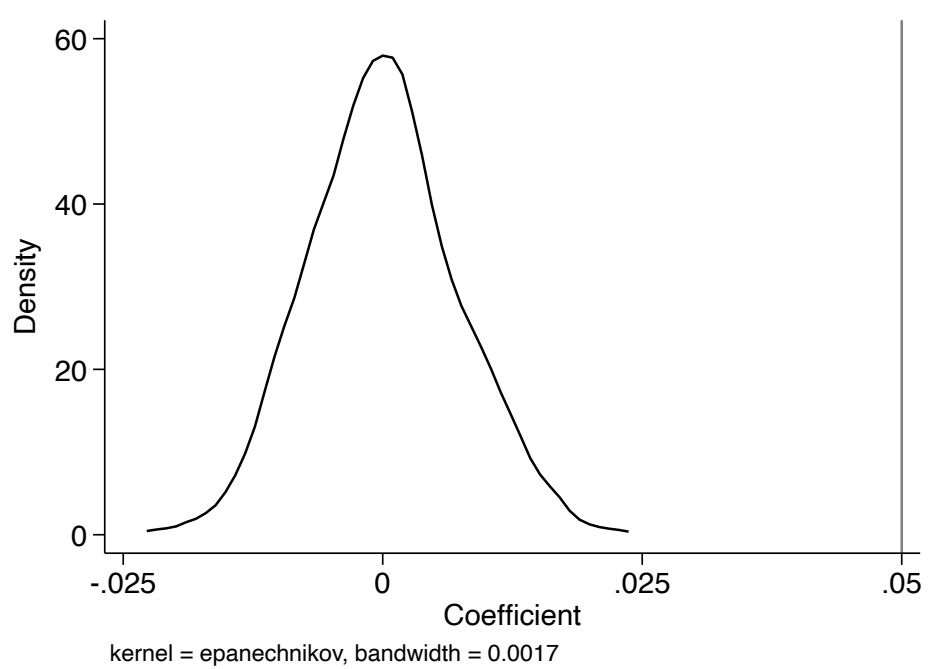

A. Any contract

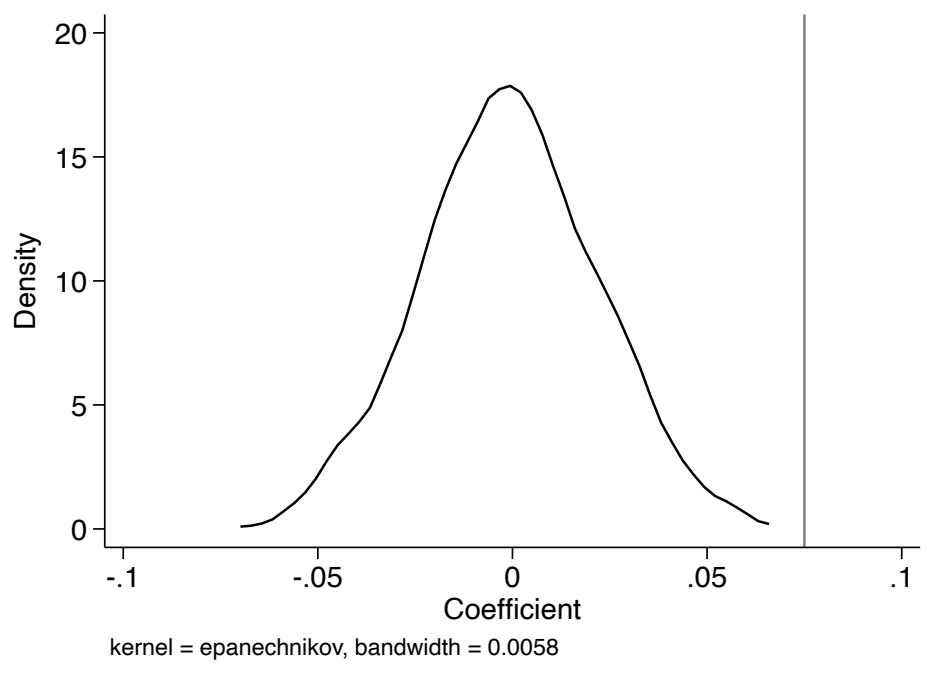

B. Ln average contract

Notes: This figure presents the distribution of placebo estimates from the main specification (4.1), where we randomly assign the predicted probability of corruption to municipalities 500 times. In both cases the probability of finding an estimate as the one presented in Table 1 is below $1 \%$. 


\section{Figure A6. Corruption and competitive contracts}

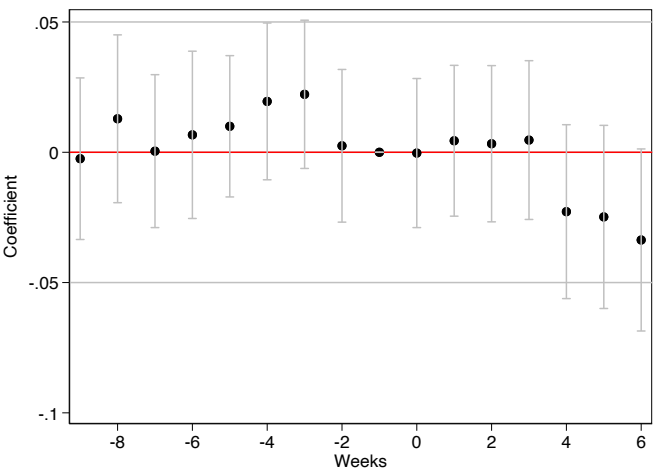

A. Any contract: Competitive

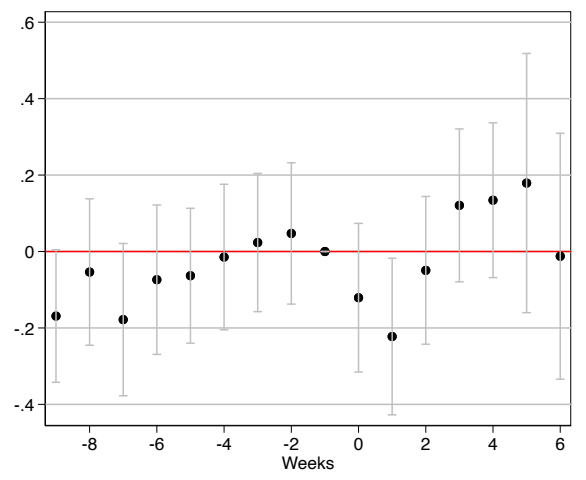

B. Ln average contract: Competitive

Notes: This figure presents the coefficients from our dynamic specification presented in equation (4.2). Panel A uses as dependent variable a dummy for at least one competitive contract, while Panel B uses as dependent variable the logarithm of the average amount of a competitive contract. We present the point estimates of the regression and the confidence of interval at the $95 \%$. 
TABle A1. Summary statistics

\begin{tabular}{|c|c|c|c|}
\hline & $(1)$ & $(2)$ & \\
\hline & Mean & Median & $\begin{array}{l}\text { Standard } \\
\text { deviation }\end{array}$ \\
\hline Any discretionary contract & 0.63 & 1.00 & 0.48 \\
\hline Ln average contract value for discretionary contracts & 16.53 & 16.45 & 1.07 \\
\hline Ln average contract value for crisis related items & 16.56 & 16.42 & 1.23 \\
\hline Ln average contract value for food items & 16.95 & 16.80 & 1.47 \\
\hline Ln average contract value for health items & 16.41 & 16.31 & 1.13 \\
\hline Any competitive contract & 0.34 & 0.00 & 0.47 \\
\hline Ln average contract value for competitive contracts & 16.58 & 16.32 & 1.74 \\
\hline Predicted probability of corruption & 0.20 & 0.18 & 0.10 \\
\hline IGA index & 64.45 & 65.75 & 9.51 \\
\hline IDI index & 72.84 & 75.61 & 11.57 \\
\hline Cost overrun alerts & 0.12 & 0.00 & 0.33 \\
\hline Any contract to campaign donor after outbreak & 0.19 & 0.00 & 0.39 \\
\hline Any direct contract to campaign donor after outbreak & 0.12 & 0.00 & 0.33 \\
\hline Any budget additions to discretionary contracts after outbreak & 0.30 & 0.00 & 0.46 \\
\hline Any budget additions to food-related items after outbreak & 0.12 & 0.00 & 0.32 \\
\hline Any budget additions to health-related items after outbreak & 0.08 & 0.00 & 0.27 \\
\hline Any time additions to discretionary contracts after outbreak & 0.29 & 0.00 & 0.45 \\
\hline Any time additions to food-related items after outbreak & 0.17 & 0.00 & 0.37 \\
\hline Any time additions to health-related items after outbreak & 0.12 & 0.00 & 0.33 \\
\hline
\end{tabular}

Notes: This table presents summary statistics for the main variables used in the empirical analysis. 


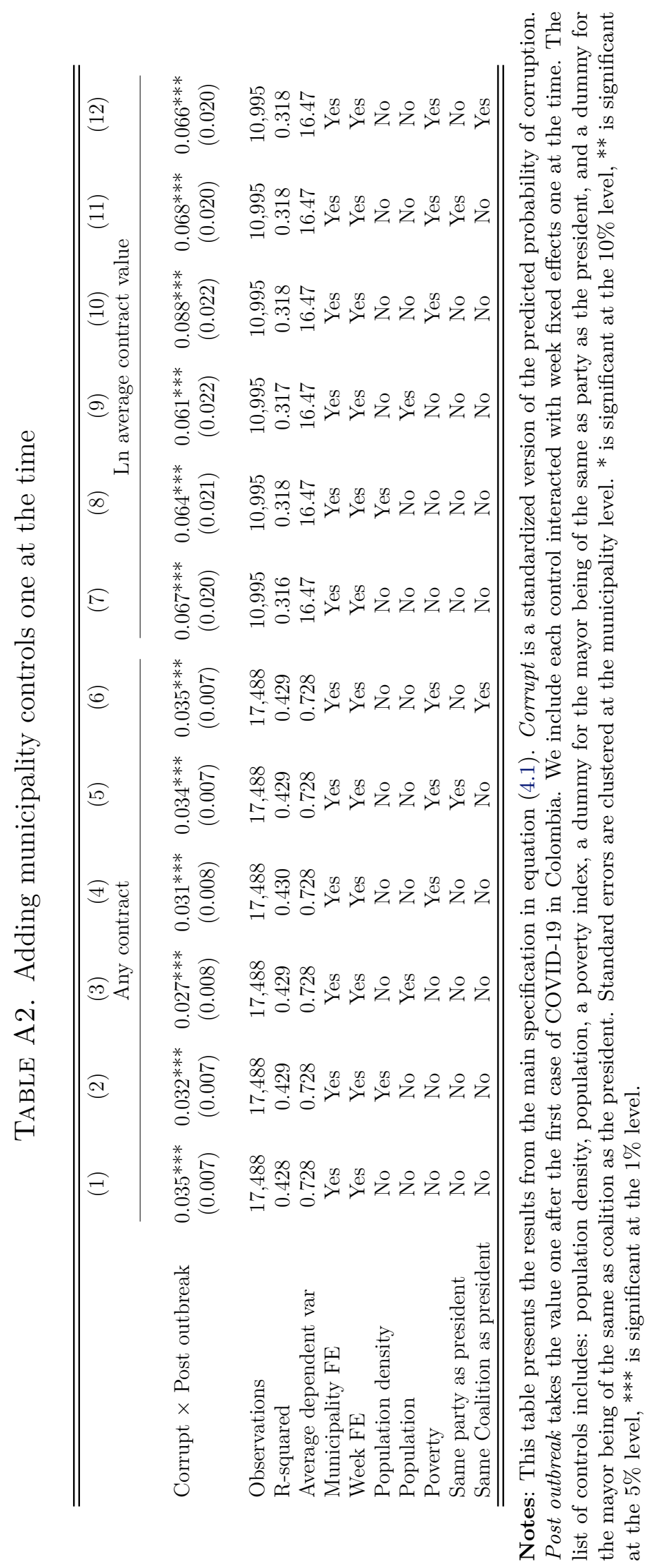




\section{TABle A3. Corruption and COVID-19 exposure}

\begin{tabular}{lccc}
\hline \hline & $\begin{array}{c}(1) \\
\text { Total } \\
\text { cases }\end{array}$ & & $\begin{array}{c}\text { Total } \\
\text { deaths }\end{array}$ \\
Corrupt & & \\
& -2.528 & & -0.061 \\
& $(1.700)$ & & $(0.168)$ \\
Observations & & & \\
R-squared & 1,090 & & 1,090 \\
Department FE & 0.753 & & 0.514 \\
Socio-demographic controls & Yes & & Yes \\
Average dependent var & 4.896 & & Yes \\
\hline \hline
\end{tabular}

Notes: This table presents the results from a cross-section specification. Corrupt is a standardized version of the predicted probability of corruption. Socio-demographic controls include population, population density, and a poverty index. Standard errors are computed using wild bootstrap. * is significant at the $10 \%$ level, ** is significant at the $5 \%$ level, $* * *$ is significant at the $1 \%$ level. 
TABLE A4. Robustness to corruption outliers

\begin{tabular}{|c|c|c|c|c|c|c|}
\hline \multirow[b]{3}{*}{ Winsorization: } & (1) & $(2)$ & $(3)$ & $(4)$ & $(5)$ & $(6)$ \\
\hline & \multicolumn{3}{|c|}{ Any contract } & \multicolumn{3}{|c|}{ Ln average contract value } \\
\hline & $1 \%$ & $2.5 \%$ & $5 \%$ & $1 \%$ & $2.5 \%$ & $5 \%$ \\
\hline Corrupt $\times$ Post outbreak & $\begin{array}{c}0.026^{* * *} \\
(0.009)\end{array}$ & $\begin{array}{c}0.026^{* * *} \\
(0.009)\end{array}$ & $\begin{array}{c}0.025^{* * *} \\
(0.009)\end{array}$ & $\begin{array}{c}0.075^{* * *} \\
(0.024)\end{array}$ & $\begin{array}{c}0.075^{* * *} \\
(0.024)\end{array}$ & $\begin{array}{c}0.079 * * * \\
(0.024)\end{array}$ \\
\hline Observations & 17,488 & 17,488 & 17,488 & 10,995 & 10,995 & 10,995 \\
\hline R-squared & 0.431 & 0.431 & 0.431 & 0.321 & 0.320 & 0.321 \\
\hline Municipality FE & Yes & Yes & Yes & Yes & Yes & Yes \\
\hline Week FE & Yes & Yes & Yes & Yes & Yes & Yes \\
\hline Socio-demographic controls & Yes & Yes & Yes & Yes & Yes & Yes \\
\hline Average dependent var & 0.728 & 0.728 & 0.728 & 16.47 & 16.47 & 16.47 \\
\hline
\end{tabular}

Notes: This table presents the results from the main specification in equation (4.1). Corrupt is a standardized version of the predicted probability of corruption. Columns 1 and 3 use a winsorized version of corrupt at $1 \%$, columns 2 and 4 at 2.5\%, and columns 3 and 6 at 5\%. Post outbreak takes the value one after the first case of COVID-19 in Colombia. Socio-demographic controls include population, population density, and a poverty index all of them interacted with week fixed effects. Standard errors are clustered at the municipality level. * is significant at the $10 \%$ level, ${ }^{* *}$ is significant at the $5 \%$ level, $* * *$ is significant at the $1 \%$ level. 
TABLE A5. Robustness to Ln average contract value outliers

\begin{tabular}{|c|c|c|c|}
\hline & $(1)$ & $(2)$ & $(3)$ \\
\hline & \multicolumn{3}{|c|}{ Ln average contract value } \\
\hline Winsorization: & $1 \%$ & $2.5 \%$ & $5 \%$ \\
\hline Corrupt $\times$ Post outbreak & $\begin{array}{c}0.077 * * * \\
(0.022)\end{array}$ & $\begin{array}{c}0.074^{* * *} \\
(0.021)\end{array}$ & $\begin{array}{c}0.069^{* * *} * \\
(0.020)\end{array}$ \\
\hline Observations & 10,995 & 10,995 & 10,995 \\
\hline R-squared & 0.345 & 0.348 & 0.350 \\
\hline Municipality FE & Yes & Yes & Yes \\
\hline Week FE & Yes & Yes & Yes \\
\hline Socio-demographic controls & Yes & Yes & Yes \\
\hline Average dependent var & 16.47 & 16.47 & 16.47 \\
\hline
\end{tabular}

Notes: This table presents the results from the main specification in equation (4.1). Corrupt is a standardized version of the predicted probability of corruption. Column 1 presents the results for Ln average contract value winsorized at $1 \%$, column 2 at $2.5 \%$, and column 3 at $5 \%$. Post outbreak takes the value one after the first case of COVID-19 in Colombia. Socio-demographic controls include population, population density, and a poverty index all of them interacted with week fixed effects. Standard errors are clustered at the municipality level. * is significant at the $10 \%$ level, $* *$ is significant at the $5 \%$ level, $* * *$ is significant at the $1 \%$ level. 
TABLE A6. Corruption and competitive contracts

\begin{tabular}{lccc}
\hline \hline & $(1)$ & & $(2)$ \\
& $\begin{array}{c}\text { Any } \\
\text { contract }\end{array}$ & & $\begin{array}{c}\text { Ln average } \\
\text { contract amount }\end{array}$ \\
\cline { 2 - 2 } Corrupt $\times$ Post outbreak & $-0.015^{*}$ & & 0.026 \\
& $(0.009)$ & & $(0.039)$ \\
Observations & 17,488 & & 5,871 \\
R-squared & 0.552 & & 0.496 \\
Municipality FE & Yes & & Yes \\
Week FE & Yes & Yes \\
Socio-demographic controls & Yes & Yes \\
Average dependent var & 0.412 & & 16.50 \\
\hline \hline
\end{tabular}

Notes: This table presents the results from the main specification in equation (4.1). Corrupt is a standardized version of the predicted probability of corruption. Post outbreak takes the value one after the first case of COVID19 in Colombia. Socio-demographic controls include population, population density, and a poverty index all of them interacted with week fixed effects. Standard errors are computed using wild bootstrap and clustered at the municipality level. * is significant at the $10 \%$ level, $* *$ is significant at the $5 \%$ level, $* * *$ is significant at the $1 \%$ level. 
TABLE A7. Drop from sample municipalities with a corrupt case

\begin{tabular}{|c|c|c|c|c|c|c|}
\hline \multirow[b]{3}{*}{ Corrupt $\times$ Post outbreak } & (1) & $(2)$ & $(3)$ & (4) & $(5)$ & $(6)$ \\
\hline & \multicolumn{3}{|c|}{ Any contract } & \multicolumn{3}{|c|}{ Ln average contract value } \\
\hline & $\begin{array}{c}0.033^{* * *} \\
(0.010)\end{array}$ & $\begin{array}{c}0.033^{* * *} \\
(0.010)\end{array}$ & $\begin{array}{c}0.037^{* * *} \\
(0.010)\end{array}$ & $\begin{array}{c}0.075^{* * *} \\
(0.026)\end{array}$ & $\begin{array}{c}0.067^{* *} \\
(0.027)\end{array}$ & $\begin{array}{c}0.051 \\
(0.032)\end{array}$ \\
\hline Observations & 15,572 & 15,572 & 15,572 & 9,562 & 9,562 & 9,562 \\
\hline R-squared & 0.440 & 0.440 & 0.443 & 0.317 & 0.317 & 0.322 \\
\hline Municipality FE & Yes & Yes & Yes & Yes & Yes & Yes \\
\hline Week FE & Yes & Yes & Yes & Yes & Yes & Yes \\
\hline Socio-demographic controls & Yes & Yes & Yes & Yes & Yes & Yes \\
\hline COVID-19 cases & No & Yes & No & No & Yes & No \\
\hline Market access & No & No & Yes & No & No & Yes \\
\hline Average dependent var & 0.714 & 0.714 & 0.714 & 16.44 & 16.44 & 16.44 \\
\hline
\end{tabular}

Notes: This table presents the results from the main specification in equation (4.1). We drop from the sample 132 with an actual investigation for corruption related to Covid-19. Corrupt is a standardized version of the predicted probability of corruption. Post outbreak takes the value one after the first case of COVID-19 in Colombia. Sociodemographic controls include population, population density, and a poverty index all of them interacted with week fixed effects. Standard errors are clustered at the municipality level. * is significant at the $10 \%$ level, ${ }^{* *}$ is significant at the $5 \%$ level, $* * *$ is significant at the $1 \%$ level. 
TABle A8. Extended sample

\begin{tabular}{|c|c|c|c|c|c|c|}
\hline \multirow[b]{3}{*}{ Panel A: Add 2 weeks } & (1) & $(2)$ & $(3)$ & $(4)$ & $(5)$ & $(6)$ \\
\hline & \multicolumn{3}{|c|}{ Any contract } & \multicolumn{3}{|c|}{ Ln average contract value } \\
\hline & & & & & & \\
\hline Corrupt $\times$ Post outbreak & $\begin{array}{c}0.024^{* * *} \\
(0.008)\end{array}$ & $\begin{array}{c}0.024^{* * *} \\
(0.008)\end{array}$ & $\begin{array}{c}0.028^{* * *} \\
(0.009)\end{array}$ & $\begin{array}{c}0.071^{* * *} \\
(0.023)\end{array}$ & $\begin{array}{c}0.066^{* * *} \\
(0.023)\end{array}$ & $\begin{array}{c}0.067^{* * *} \\
(0.026)\end{array}$ \\
\hline Observations & 19,674 & 19,674 & 19,674 & 11,844 & 11,844 & 11,844 \\
\hline R-squared & 0.453 & 0.453 & 0.457 & 0.319 & 0.319 & 0.325 \\
\hline Average dependent var & 0.728 & 0.728 & 0.728 & 16.47 & 16.47 & 16.47 \\
\hline \multicolumn{7}{|l|}{ Panel B: Add 4 weeks } \\
\hline Corrupt $\times$ Post outbreak & $\begin{array}{c}0.026^{* * *} \\
(0.008)\end{array}$ & $\begin{array}{c}0.025^{* * *} \\
(0.008)\end{array}$ & $\begin{array}{c}0.031^{* * *} \\
(0.008)\end{array}$ & $\begin{array}{c}0.084^{* * *} \\
(0.021)\end{array}$ & $\begin{array}{c}0.081^{* * *} \\
(0.021)\end{array}$ & $\begin{array}{c}0.084^{* * *} \\
(0.024)\end{array}$ \\
\hline Observations & 21,860 & 21,860 & 21,860 & 13,424 & 13,424 & 13,424 \\
\hline R-squared & 0.428 & 0.428 & 0.432 & 0.312 & 0.312 & 0.318 \\
\hline Average dependent var & 0.728 & 0.728 & 0.728 & 16.47 & 16.47 & 16.47 \\
\hline \multicolumn{7}{|l|}{ Panel C: Add 6 weeks } \\
\hline Corrupt $\times$ Post outbreak & $\begin{array}{c}0.027^{* * *} \\
(0.008)\end{array}$ & $\begin{array}{c}0.027^{* * *} \\
(0.008)\end{array}$ & $\begin{array}{c}0.034^{* * *} \\
(0.008)\end{array}$ & $\begin{array}{c}0.080 * * * \\
(0.020)\end{array}$ & $\begin{array}{c}0.077^{* * *} \\
(0.020)\end{array}$ & $\begin{array}{c}0.081^{* * *} \\
(0.023)\end{array}$ \\
\hline Observations & 24,046 & 24,046 & 24,046 & 14,928 & 14,928 & 14,928 \\
\hline R-squared & 0.406 & 0.406 & 0.410 & 0.307 & 0.307 & 0.312 \\
\hline \multicolumn{7}{|l|}{ Panel D: Add 8 weeks } \\
\hline Corrupt $\times$ Post outbreak & $\begin{array}{c}0.030 * * * \\
(0.008)\end{array}$ & $\begin{array}{c}0.029^{* * *} \\
(0.008)\end{array}$ & $\begin{array}{c}0.037^{* * *} \\
(0.008)\end{array}$ & $\begin{array}{c}0.074^{* * *} \\
(0.019)\end{array}$ & $\begin{array}{c}0.072^{* * *} \\
(0.019)\end{array}$ & $\begin{array}{c}0.074^{* * *} \\
(0.022)\end{array}$ \\
\hline Observations & 26,232 & 26,232 & 26,232 & 16,416 & 16,416 & 16,416 \\
\hline R-squared & 0.389 & 0.389 & 0.393 & 0.302 & 0.302 & 0.307 \\
\hline \multicolumn{7}{|l|}{ Panel E: Add 10 weeks } \\
\hline Corrupt $\times$ Post outbreak & $\begin{array}{c}0.034^{* * *} \\
(0.007)\end{array}$ & $\begin{array}{c}0.034^{* * *} \\
(0.007)\end{array}$ & $\begin{array}{c}0.039^{* * *} \\
(0.008)\end{array}$ & $\begin{array}{c}0.078^{* * *} \\
(0.019)\end{array}$ & $\begin{array}{c}0.076^{* * *} \\
(0.019)\end{array}$ & $\begin{array}{c}0.076^{* * *} \\
(0.021)\end{array}$ \\
\hline Observations & 28,418 & 28,418 & 28,418 & 17,686 & 17,686 & 17,686 \\
\hline R-squared & 0.375 & 0.375 & 0.378 & 0.292 & 0.293 & 0.297 \\
\hline Municipality FE & Yes & Yes & Yes & Yes & Yes & Yes \\
\hline Week FE & Yes & Yes & Yes & Yes & Yes & Yes \\
\hline Baseline controls & Yes & Yes & Yes & Yes & Yes & Yes \\
\hline COVID-19 cases & No & Yes & No & No & Yes & No \\
\hline Market access & No & No & Yes & No & No & Yes \\
\hline
\end{tabular}

Notes: This table presents the results from the main specification in equation (4.1). Corrupt is a standardized version of the predicted probability of corruption. Post outbreak takes the value one after the first case of COVID-19 in Colombia. Baseline controls include population, population density, and a poverty index all of them interacted with week fixed effects. Standard errors are clustered at the municipality level. * is significant at the $10 \%$ level, ** is significant at the $5 \%$ level, $* * *$ is significant at the $1 \%$ level. 


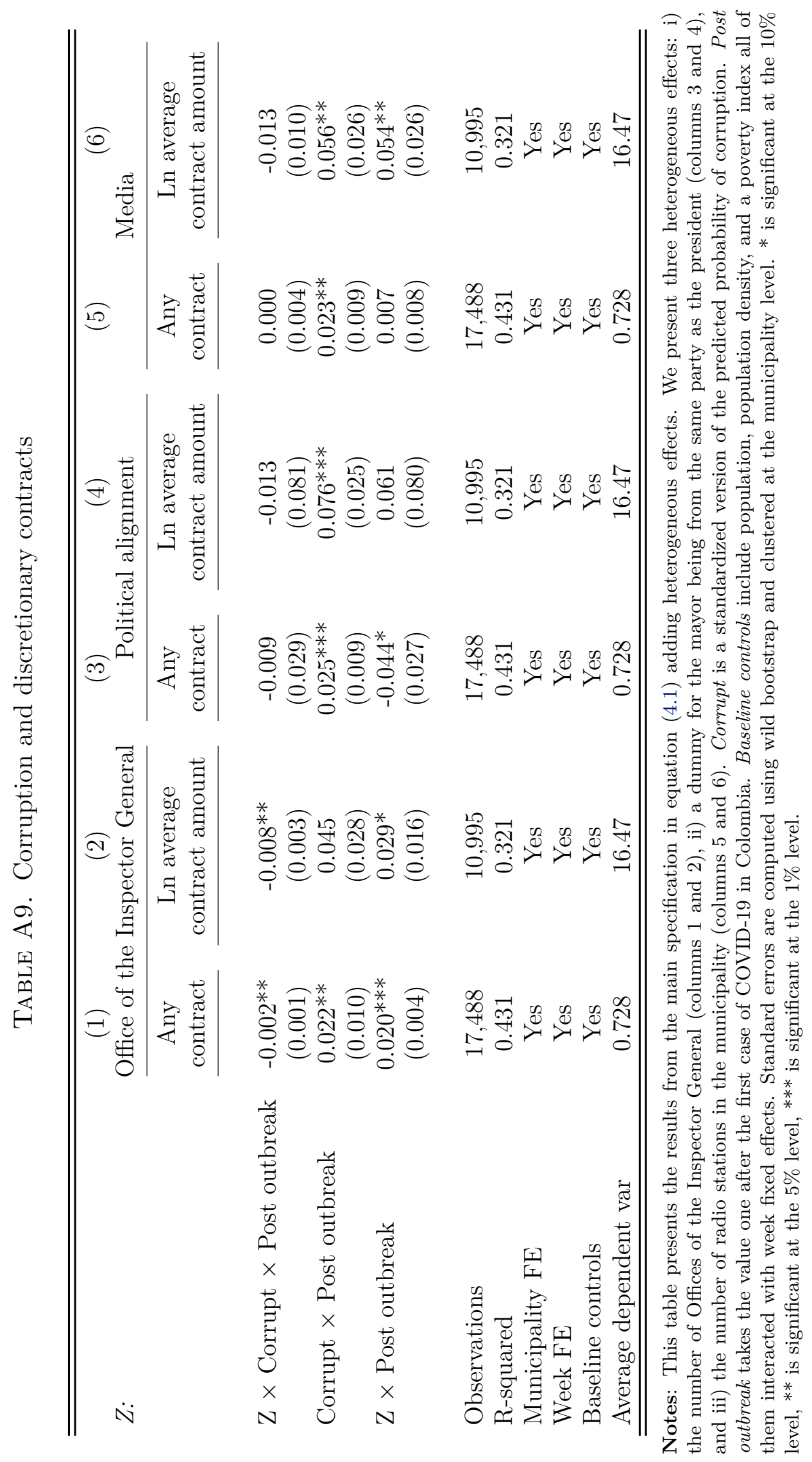

